\title{
General and Partial Equilibrium Modeling of Sectoral Policies to Address Climate Change in the United States
}

\author{
William Pizer, Dallas Burtraw, Winston \\ Harrington, Richard Newell, James Sanchirico \\ and Michael Toman
}

March 2003・ Draft Working Paper

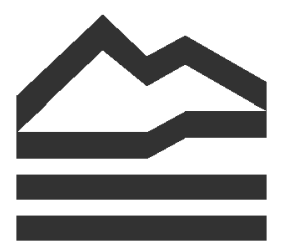

\section{RESOURCES}

FOR THE FUTURE

Resources for the Future

1616 P Street, NW

Washington, D.C. 20036

Telephone: 202-328-5000

Fax: 202-939-3460

Internet: http://www.rff.org

(C) 2003 Resources for the Future. All rights reserved. No portion of this paper may be reproduced without permission of the authors.

Discussion papers are research materials circulated by their authors for purposes of information and discussion. They have not necessarily undergone formal peer review or editorial treatment. 


\title{
General and Partial Equilibrium Modeling of Sectoral Policies to Address Climate Change in the United States
}

\author{
William Pizer, Dallas Burtraw, Winston Harrington, Richard Newell, James Sanchirico \\ and Michael Toman
}

\begin{abstract}
This document provides technical documentation for work using detailed sectoral models to calibrate a general equilibrium analysis of market and non-market sectoral policies to address climate change. Results of this work can be found in the companion paper, "Modeling Costs of Economy-wide versus Sectoral Climate Policies Using Combined Aggregate-Sectoral Models".
\end{abstract}

Key Words: carbon, policy, general, partial, equilibrium, model, cost

JEL Classification Numbers: Q25, D58, D61, Q48 


\section{Contents}

1. General Equilibrium Model........................................................................................... 1

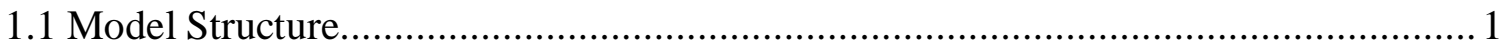

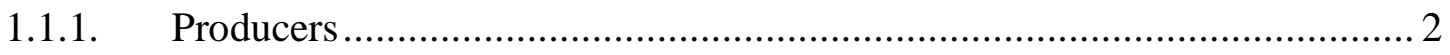

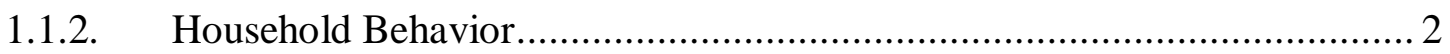

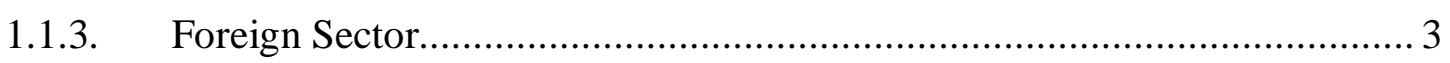

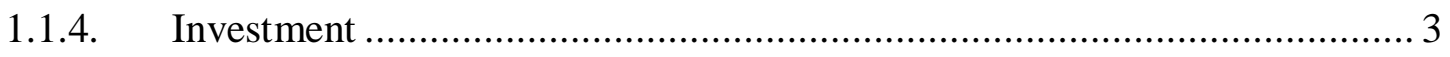

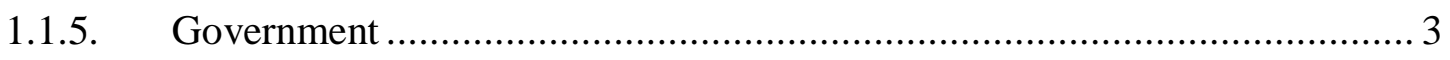

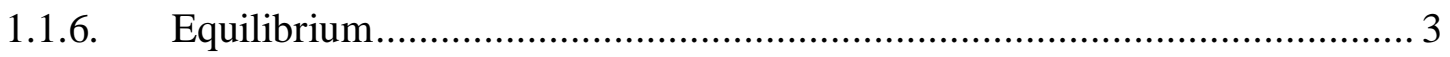

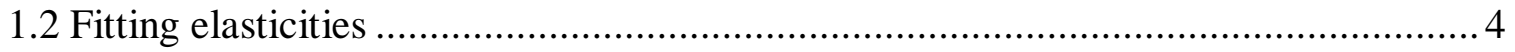

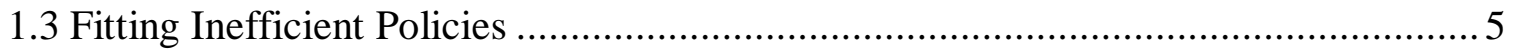

2. Electricity Production Model............................................................................................. 7

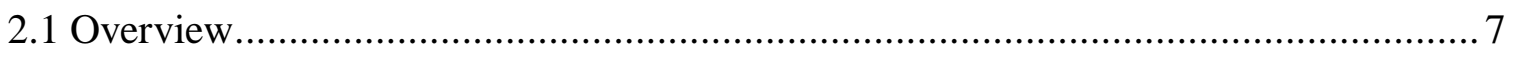

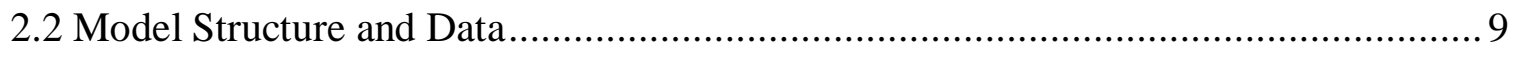

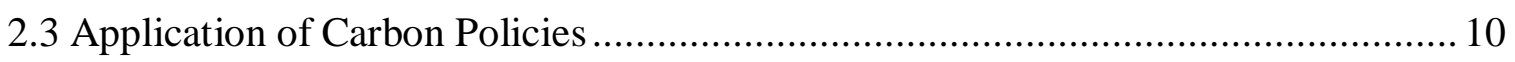

3. Industrial Production Model ................................................................................ 11

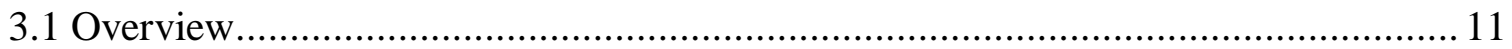

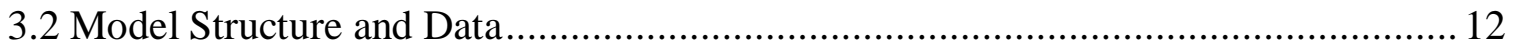

3.3 Application of Carbon Policies ....................................................................... 15

4. Household Transportation Model ...................................................................................... 16

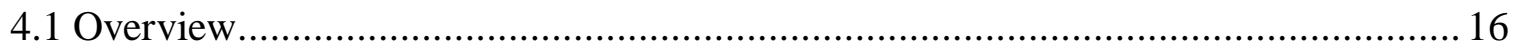

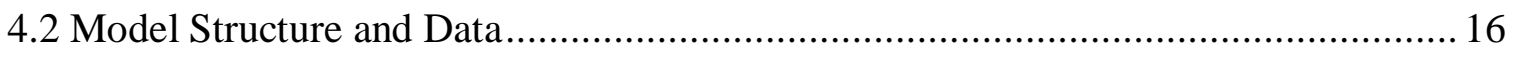

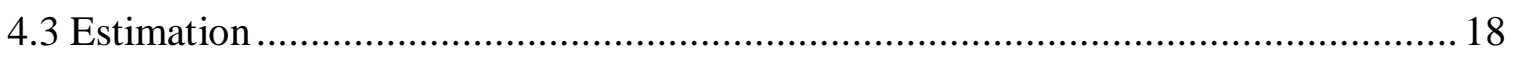

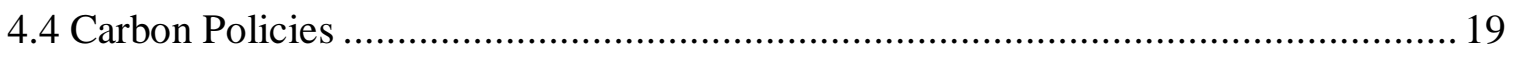

5. Discrete-Continuous Choice Model of Energy Demand .................................................... 20

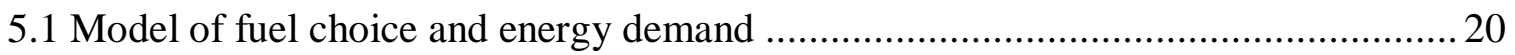

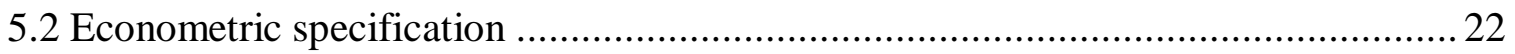

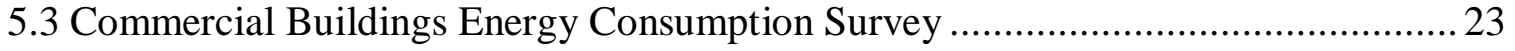

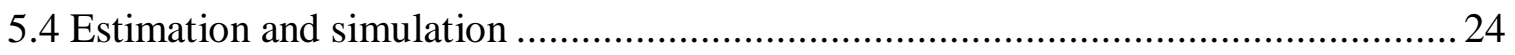

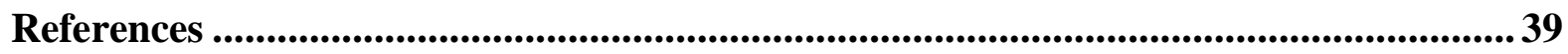




\title{
General and Partial Equilibrium Modeling of Sectoral Policies to Address Climate Change in the United States
}

\author{
William Pizer, Dallas Burtraw, Winston Harrington, Richard Newell, James Sanchirico \\ and Michael Toman*
}

\section{General Equilibrium Model}

\subsection{Model Structure}

The model is centered around ten production sectors, distinct household and government agents, fixed real investment, and a standard model of relatively inelastic import supply and elastic export demand. The ten production sectors provide particular detail on fossil fuel use (coal, petroleum, natural gas) in order to monitor carbon dioxide emissions. The structure separates industry, commercial buildings, and transportation equipment for more detailed policy modeling. We also create a household transportation sector that combines household capital (cars), gasoline, and retail services into a good consumed by the household. This allows us to model CAFE policies. The exact composition of these sectors based on Input-Output Classification Codes is in Table 1. Table 2 shows the flow of goods between sectors and final demand.

In its comprehensive representation of the U.S. economy, this model captures all energy and fossil fuel use, even those uses that have not been the focus of our more detailed modeling efforts. Government use of energy, for example, is captured along with commercial transportation, military and construction.

\footnotetext{
* Pizer, Newell and Sanchirico are Fellows, and Burtraw and Harrington are Senior Fellows, at Resources for the Future. Toman was previously a Senior Fellow and is now Senior Economist in the Environment Division at the Inter-American Development Bank. The authors appreciate outstanding assistance from Ranjit Bharvirkar, Matt Cannon, Kenny Gillingham, Martin Heintzelman, David Lankton and Anthony Paul. We acknowledge financial support from U.S. Department of Energy grant DE-FG02-98ER62702. All errors and opinions remain the responsibility of the authors. Address correspondence to Pizer, Resources for the Future, 1616 P Street NW, Washington DC 20036 (email: pizer@rff.org).
} 


\subsubsection{Producers}

The model includes ten production sectors that combine ten composite domestic-import goods with labor, capital and non-competitive imports to produce a single output. We currently assume a hierarchical structure, shown in Figure 1, with capital, labor, energy and materials at the top level, and energy and materials formed by a combination of the ten domestic-import composite goods and non-competitive imports. Each tier is assumed to have a constant elasticity of substitution, with the material elasticity fixed at zero (Leontief). In the household transportation sector, energy (gasoline) and materials (retail services) are combined with a zero elasticity in a single sub-tier.

The two elasticities at the top tier and within the energy tier, $\sigma_{e}$ and $\sigma_{t o p}$, are estimated as described in Section 1.2 for the sectors where detailed models exist--industry (as well as transportation equipment), commercial buildings, electricity, and household transportation. In other sectors we borrow values from McKibbin et al. (1999).

\subsubsection{Household Behavior}

Households are endowed with capital and labor equal to the sum of factor inputs to all ten sectors as well as an imputed quantity of leisure. ${ }^{1}$ The income from these endowments is used to buy a fixed (real) amount of the aggregate investment good along with an aggregate consumption good composed of the ten composite domestic-import goods, non-competitive imports, and leisure. We assume a tiered structure for household preferences, shown in Figure 2, where at the lowest tier, non-energy, non-transportation goods are combined with a unit elasticity of substitution. Transportation is then added in with an elasticity of substitution equal to 1.08 (estimated from our transportation model simulations). The next tier brings in energy with an elasticity of substitution of 0.25, a number taken from the existing literature (Dahl 1993). Among individual household fuels (electricity, natural gas, and fuel oil), we assume an elasticity of $0.05 .^{2}$ Finally, we assume an elasticity of substitution of 0.11 between leisure and the aggregate consumption good based on Wales and Woodland (1976).

\footnotetext{
${ }^{1}$ Based on the assumption that currently one-third of the total time endowment is consumed as leisure.

${ }^{2}$ We were unable to find an estimate of the elasticity of substitution among household fuels in the literature. Fitting our tiered model of household energy demand to the aggregate time series from 1983-2000, we find an elasticity of substitution among fuels of 0.01 (s.e. 0.05) and an elasticity of substitution between energy and other goods of 0.10 (s.e. 0.08). Rather than using our point estimate, we used this empirical evidence to support the use of a very low number (which still falls within the error bounds).
} 


\subsubsection{Foreign Sector}

Imports of foreign goods are combined with similar domestic goods using a standard Armington model with elasticities of 3.0 based on Ballard et al (1985) to produce the composite import-domestic good. Imports are supplied with an elasticity of 0.465 (relative to the imported good price divided by the price of foreign exchange) and exports are demanded with an elasticity of 10 (relative to the composite import-domestic good price divided by the price of foreign exchange). Foreign savings is fixed in real terms. The price of foreign exchange adjusts so that the value of net exports, plus foreign savings, equals zero.

\subsubsection{Investment}

The aggregate investment good is composed of the ten composite import-domestic goods and with a unit elasticity of substitution. We hold the aggregate quantity of the investment good fixed in all simulations, thereby fixing the level of real savings by households and the foreign sector.

\subsubsection{Government}

Like the investment sector, the government purchases an aggregated government good composed of ten composite import-domestic goods and non-competitive imports. We hold the aggregate quantity of the government good fixed in all simulations, thereby fixing the level of real government services. Unlike the investment good, however, the government good is purchased with tax revenues on output (via the indirect business tax), factor endowments (via an income tax) and, under some policy simulations, carbon (via taxes on domestic use of coal, oil and natural gas). In the benchmark simulation, the income tax rate is determined in order to set the government deficit to zero (roughly 15\%). In policy simulations, the income tax rate is adjusted in order to keep the deficit at zero.

\subsubsection{Equilibrium}

Equilibrium in the model is defined by supply meeting demand for all goods, zero profit in all sectors, and a binding income constraint for households. Real savings by the foreign sector and households is held fixed. We do this to avoid changes in immeasurable future welfare due to changes in the capital stock. As noted above, real government spending is also held fixed (to avoid welfare affects related to changes in the provision of public goods). 


\subsection{Fitting elasticities}

For each detailed sectoral model, our approach is first to construct a similar reduced-form sectoral model from the benchmark input-output accounts (Lawson 1997). We then use simulations of the detailed sectoral models to calibrate elasticities in the reduced-form model. In particular, we use a nested constant elasticity of substitution (CES) functional form for the reduced form models. The top nest involves substitution between capital, labor, energy, and materials (KLEM). Energy inputs—coal, petroleum, natural gas, and electricity-comprise one sub-nest. The remaining commodities comprise the material sub-nest. We assume that materials have zero elasticity of substitution among one another and use simulations of the detailed sectoral models to determine the energy $\left(\sigma_{e}\right)$ and KLEM $\left(\sigma_{\text {top }}\right)$ elasticities. ${ }^{3}$ The nested CES model is shown diagrammatically in Figure 1.

To determine the elasticities, we simulate the effect of a carbon tax on use of fossil fuels and electricity in the detailed sectoral models. With multiple data points between zero and about $\$ 60$ per ton of carbon, we attempt to match the percentage changes in fuel demand predicted by the reduced-form model using the same percentage changes in fuel prices. Elasticities are chosen to minimize the sum of squared errors in percent changes in fuel given by the reducedform model compared to the detailed sectoral model results, weighting by fuel expenditure. That is, we choose the elasticities $\sigma_{e}$ and $\sigma_{t o p}$ to minimize

$$
\sum_{e, n}\left(w_{e}\left(x_{e, n}-\bar{x}_{e, n}\right)\right)^{2}
$$

by searching over various combinations of these parameters .Here the summation is over both fuels $e$ (coal, oil, natural gas, and electricity) and $n$ distinct simulated carbon taxes. The variable $x_{e, n}$ is the percent change in use of fuel $e$ for carbon tax $n$ predicted by the reduced form model, $\bar{x}_{e, n}$ is similarly the predicted change in the detailed sectoral model, and $w_{e}$ is the expenditure on

\footnotetext{
${ }^{3}$ Household transportation is treated differently because it does not exist in the input-output accounts. We create it from a combination of household purchases of gasoline and an imputed capital stock. Household purchases of gasoline are separated from home heating oil based on Table 2.2, 1992 National Income and Product Accounts (from the BEA website; see BEA 2002). The imputed capital stock of household vehicles is based on the ratio of consumer vehicles capital stock to total private capital in 1992 from Table 1.1 of the detailed data on fixed assets and consumer durable goods (from the BEA website; see Herman 2000). This sector is also different in that we use simulated data to estimate a KLEM elasticity and an elasticity of substitution between household transportation and consumption of other market goods.
} 
fuel $e$ in the reduced form model (from the input-output tables). Estimated elasticities are shown in Table 3.

While we fit changes in individual fuel use based on changes in fuel prices, our ability to match the carbon dioxide abatement schedule is important given our interest in policies to reduce carbon dioxide emissions. Even with a close fit based on (1), deviations are possible because the reduced form model necessarily uses cruder measures of carbon content. While the detailed sectoral models track physical quantities, the reduced-form model relies on input-output accounts that only contain dollar flows. Carbon content is assigned to the dollar flows coming from coal, natural gas utilities, and petroleum refining based on emission data by fuel and major sectortransportation, residential, commercial, industry, and electricity. ${ }^{4}$ It is also possible that the mix of fuels differs between the reduced-form model, based on the 1992 input-output tables, and the detailed sectoral models, based on a variety of more detailed sources.

Figure 3 shows compares the detailed and reduced-form marginal cost schedules for the four sectors we fit. The reduced-form schedules for industry and transportation come out slightly more elastic than the detailed model results; commercial buildings slightly less. The errors are on the order of $10 \%$. The marginal cost schedules for electricity look a bit different. While they match at around $\$ 60$ per ton, the detailed model shows a concave schedule and the reduced-form a convex schedule. The concave schedule arises because significant reductions do not begin to appear until the relative cost of coal rises sufficiently to encourage fuel switching. The reduced-form schedule is also more elastic because, based on 1992 data, there are more opportunities to fuel switch because of relatively higher usage of coal and oil versus natural gas.

\subsection{Fitting Inefficient Policies}

In addition to using the detailed sectoral models of electricity, household transportation, commercial buildings, and industry to fit elasticities in reduced-form nested CES models, we

\footnotetext{
${ }^{4}$ Based on our calculations, carbon content for coal ranges from 21 to 29 tons per thousand dollars, for petroleum from 0.7 to 8.0 tons per thousand dollars, and for natural gas from 0.9 to 9.0 tons per thousand dollars. The value depends on the quality of the product (for example, gasoline is a higher quality product than fuel oil) and the bargaining power of the purchaser (coal and natural gas prices are lower for electricity generators compared to industrial users). The calculations are based on dividing residential, commercial, industrial, and electricity emissions by fuel by the value of coal, oil, and natural gas used by roughly the same group. More detailed information on the coal, oil, and gas sectors allows us to avoid counting material purchases of own-sector goods as carbon-emitting fuel use.
} 
also want to model non-market policies. In particular, we are interested in fuel economy standards for consumer vehicles, regionalized emission limits in electricity, and performance standards in industry. While it is relatively straightforward to simulate these policies in the detailed models, how can they be represented in the reduced form models?

Simulation results from the detailed models provide data on how production changes in response to these policies - that is, changes in inputs as output is held fixed (in some cases, the detailed models include the demand response of output). Our goal is to replicate these observed changes in a model with competitive markets and simple production functions. That is, we want to cause production to shift from one combination of inputs to another in the absence of an external price change. There are several ways to replicate these results in a reduced form model.

Without changing the model parameters, we could impose constraints that shift production. For example, fuel economy requirements on automobiles might suggest a maximum ratio of fuel to output. We could also change the technology. Regional emission limits for power plants imply, at the same prices and total electricity supplied, lower fossil fuel consumption (or more natural gas and less coal / oil). We could imagine a different production technology that led to this choice. Both of these approaches require us to add or change the production function to cause input use to shift.

Rather than changing the production technology, suppose we imagined that firms suddenly saw the internal cost of using particular inputs diverging from market prices. For example, a fuel economy standard would make fuel use appear more costly to the firm, even if the market price of the fuel is the same-it uses up flexibility with respect to the standard. This suggests modeling inefficient policies as a change in the prices contemplated by the firm, even as the market prices remain unchanged. This is easy to implement as revenue neutral taxes and subsidies; if no net revenue is generated, payments by the firm exactly equal input costs at market prices. This is true despite the fact the taxes and subsidies change the prices used by the firm to configure their production strategy. We call these shadow taxes because they do not really tax the firm on net, but change the relative price of inputs. We also allow for a Hicks neutral productivity shock - requiring proportionally more inputs for a given output level— because in some cases policies not only shift input usage along a production frontier but also lead to non-productive expenses.

Absent any price or output-level changes, the various approaches described so far can be used to cause equivalent shifts in production under an inefficient policies. Where the approaches diverge, however, is when market prices and output-levels change. In the shadow tax approach 
we use, the ad valorem level of the shadow price remains fixed. If, in fact, some kind of quantitative constraint exists, we would imagine the shadow tax rising or falling to keep the constraint met. On the other hand, if the inefficient policy is more like a performance standardparticularly a tradable performance standard-we would imagine that shadow tax remaining relatively constant. Tradable CAFE, a policy considered in a recent National Research Council study of fuel economy standards, would be a prime example. ${ }^{5}$

The vector of shadow taxes and productivity shocks is estimated in the same manner as the elasticities. Data from the detailed models is matched, as closely as possible, to predictions from the reduced-form model by minimizing the squared error in (1). The results are shown in Table 4. The results indicate no productivity effects associated with the various inefficient policies-only shifts along the production frontier. This may be because there are, in fact, no productivity effects. It may also arise because in some of the detailed models (household transportation and industry) we do not have measures of overall cost—only responses for a subset of inputs and outputs. ${ }^{6}$ This makes it more difficult to identify lost productivity. The productivity effects may also be small relative to the shifts along the production frontier. Effects on the remaining inputs are sensible. Energy prices increase relative to other inputs, and coal increases more than oil, which increases more than natural gas. Note that the parameters in Table 4 reflect the inefficient policy operating at a particular level. We take that level to be scaleable and consider the marginal effects of ramping up the inefficient policies to achieve different emission goals.

\section{Electricity Production Model}

\subsection{Overview}

The Haiku electricity sector model is a simulation model developed by RFF that describes regional electricity markets and inter-regional electricity trade with an integrated algorithm for investment and retirement of generation capacity, fuel choice, and emission control

\footnotetext{
5 See NRC (2002).

6 The household transportation model does not provide a sectoral output measure-e.g., transportation servicesand makes predictions holding income constant. Without a utility measure, there is no analog to cost.
} 
technology choice. ${ }^{7}$ The model uses iteration to converge to market equilibria subject to constraints on consumer demand functions, supply technology and inter-regional transmission capability.

The Haiku model simulates equilibrium in regional electricity markets and inter-regional electricity trade with an integrated algorithm emission control technology choice. The model calculates electricity demand, electricity prices, the composition of electricity supply, interregional electricity trading activity, and emissions of key pollutants such as $\mathrm{NO}_{X}, \mathrm{SO}_{2}, \mathrm{CO}_{2}$, and mercury from electricity generation. The model solves for the quantity and price of electricity delivered in 13 regions, for four time periods (super-peak, peak, shoulder, and baseload hours) in each of three seasons (summer, winter, and spring/fall). For each of these 156 segments, demand is aggregated from three customer classes: residential, industrial, and commercial. Supply is aggregated from the complete set of electricity plants in the United States, which for modeling purposes are aggregated into 48 representative plants in each region. Investment in new generation capacity and retirement of existing facilities are determined endogenously in a dynamic framework, based on capacity-related costs of providing service in the future ("going forward costs"). Generator dispatch in the model is based on the minimization of short run variable costs of generation.

Inter-regional power trading is identified as the level of trading necessary to equilibrate regional electricity prices (accounting for transmission costs and power losses). These interregional transactions are constrained by the assumed level of available inter-regional transmission capability as reported by the North American Electric Reliability Council (NERC). Factor prices, such as the cost of capital and labor, are held constant. Fuel price forecasts are calibrated to match EIA price forecasts for 2002 (EIA 2001). Fuel market modules for coal, natural gas and biomass calculate prices that are responsive to factor demand. Coal is differentiated along several dimensions, including fuel quality and location of supply, and both coal and natural gas prices are differentiated by point of delivery. All other fuel prices are specified exogenously. For control of conventional pollutants, the model plans for flue gas desulfurization (scrubbers). Unscrubbed coal plants have the option to add a retrofit $\mathrm{SO}_{2}$

\footnotetext{
${ }^{7}$ Haiku has been used for a number of reports and articles that appear in the peer-reviewed literature. See for example: Burtraw et al (2003al; 2003b). The model has been compared with other simulation models as part of two series of meetings of Stanford University's Energy Modeling Forum (Energy Modeling Forum 2001, 1998). The model is documented in Paul and Burtraw (2002).
} 
scrubber, and all plants select from a series of coal types that vary by sulfur content and price as a strategy to reduce $\mathrm{SO}_{2}$ emissions. For control of $\mathrm{NO}_{x}$, each plant solves for the least costly post-combustion investment from the options of selective catalytic reduction (SCR) and selective noncatalytic reduction and re-burn. Utilization of each plant is flexible and demand also may respond to changes in price in order to help achieve emission reductions.

Special attention is given to the flexible modeling of institutions in the electricity sector, both with regards to the way prices are set (regulated versus competitive regional markets) and the design of environmental regulations. These include fuel specific carbon taxes or Btu taxes, new source performance standards, old source performance standards, renewable portfolio standards and regionally specific policies, incentive based approaches including emission taxes, cap and trade permit systems, affecting subsets of generators. Also modeled are a variety of systems for handling tax revenues or allocating emission permits, including auctions, grandfathering, output based allocations, and hybrid combinations.

\subsection{Model Structure and Data}

The Haiku model solves using an iterative algorithm that strives to achieve an equilibrium that satisfies all the constraints imposed upon the model. To do this, many endogenous variables are specified as control variables, and then iteratively adjusted until all constraints are satisfied. These control variables are a minimum set that provides adequate latitude to achieve equilibrium. The control variables are as follows:

1. nameplate capacity by model plant (investment, retirement);

2. electricity, generation, and reserve prices;

3. fuel costs (coal, natural gas, and biomass);

4. interregional power trading quantity and price;

5. pollution controls and allowance prices;

6. stranded assets;

7. seasonal allocation of scheduled outages;

8. allocation of hydroelectric generation over time blocks;

9. real cost of capital;

10. percentage of biomass cofiring by model plant;

11. price of renewable portfolio standard (RPS) permits; and

12. value of demand conservation incentive (DCI).

The supply data used in Haiku are primarily from databases constructed from forms compiled by the Energy Information Administration (EIA) and from the Federal Energy Regulatory Commission (FERC), supplemented with data from the Environmental Protection 
Agency (EPA). Data from public sources are supplemented in some cases with data coming from specific industry studies that address one technology or region of the country.

The demand data used in Haiku rely primarily on information collected by the Energy Information Administration. Most of the estimates of the elasticity of demand are drawn from the academic literature, occasionally supplemented for a particular region by a specialized source of data.

For each control variable, Haiku makes an initial guess at its value and then solves the remainder of the model (one iteration). Using the constraints described in detail in the model documentation (Paul and Burtraw 2002), Haiku determines, for each control variable, what its value should have been assuming that all other control variables are unchanged. Because of the partial equilibrium nature of this calculation, it yields a new set of control variable values that may still not be internally consistent. So on the next iteration, Haiku does not use exactly this partial equilibrium value for each control variable, but instead uses a value that is between the previous guess and the partial equilibrium value. This new set of control variable assumptions may also not be internally consistent, but it moves the model closer to a set of control variables that are in equilibrium.

The selection of a precise new value for each control variable (between the previous guess and the partial equilibrium value) is vital for timely and accurate convergence of the model. Haiku employs a method of intelligent adjustments to the previous guesses that cause the control variables to converge toward equilibrium by making increasingly smaller adjustments, while allowing the control variables latitude to rectify large disequilibria.

\subsection{Application of Carbon Policies}

An early version of the Haiku model was developed prior to this project, and significant enhancements have been achieved during this project. The most important of these was development of endogenous investment and retirement of generation capacity, and to expand the set of supply and demand side investment options. Also the model was developed so to be able to accommodate regionally specific greenhouse gas policies, to include a variety of regulatory approaches and to include comprehensive supply side investment options. Demand side investment options are integral to the customer-specific, time and region-specific demand functions.

An important extension for the modeling of carbon policies is the modeling of environmental policies as they would be implemented with the specific institutional setting of the 
electricity sector. This is an important feature in order to be able to characterize the large set of real-world policies in practice. The capable features of the model include new source performance standards, old source performance standards, tradable emission allowances, taxes, adders, new source review, support for renewables, and various schemes for allocating emission allowances or recycling revenues, which instill especially powerful incentives for changes in generation capacity. These features can be differentiated by region of the country, so that regions can adopt policies independently or in synchronized fashion with separate or unified trading regions.

\section{Industrial Production Model}

\subsection{Overview}

The Industrial Sector Model (INSECT) developed for this project by RFF is based on the National Energy Modeling System's industrial sector demand module (EIA 1999); it is programmed using Analytica. INSECT distinguishes 15 industry groups, for which it forecasts the demand for 13 main fuels in 4 geographic regions. The model generates the quantity consumed of each fuel along with non-utility electricity generation and corresponding steam production. The model also calculates carbon emissions based on the carbon contents of the fuels used. See the NEMS documentation (EIA 1999) for detail on the model structure.

INSECT covers energy demand from both manufacturing (SIC 20-39) and nonmanufacturing sectors (SIC 1-2, 10-17), with industry group classifications chosen to be as consistent as possible with the Manufacturing Energy Consumption Survey (MECS). The industry groups are categorized into 3 broad classes for different modeling treatment: energy-

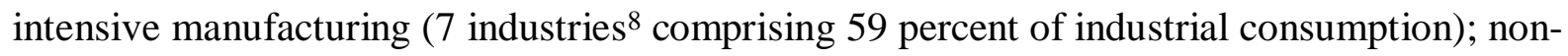
energy-intensive manufacturing ( 2 industries ${ }^{9}$ comprising 21 percent); and non-manufacturing (6 industries ${ }^{10}$ comprising 20 percent). INSECT includes energy use for primary energy extraction

\footnotetext{
${ }^{8}$ Food and kindred products (SIC 20); paper and allied products (SIC 26); bulk chemicals (SICs 281, 282, 286, and 287); glass and glass products (SICs 3211, 3221, and 3229); hydraulic cement (SIC 3241); blast furnaces and basic steel products (primarily SIC 331); and aluminum primarily SICs 3334 and 3353). Petroleum refining (SIC 2911) is modeled separately.

${ }^{9}$ Metals-based durables (SIC 34, 35, 36, 37, 38); and other manufacturing (all remaining manufacturing SIC).

10 Agriculture-crops (SIC 01); agriculture-other (SIC 02, 07, 08, 09); coal mining (SIC 12); oil/gas extraction (SIC 13); other mining (SIC 10, 14); and construction (SIC 15, 16, 17).
} 
(e.g., coal mining, natural gas and oil wells); processing and transportation of fuels is covered in the integrating module, but not in one of the detailed sectoral models. Energy use for transportation equipment manufacturing is covered in INSECT. All energy use for freight transportation services - including shipment of intermediate products, materials, and final goods-is covered in the integrating module, but not in one of the detailed sectoral models

We chose to base INSECT on the NEMS industrial demand module for several reasons. First, the NEMS industrial module has, to our knowledge, undergone more development effort, peer review, and testing than any other model of US industrial energy demand. Second, it offers a straightforward platform for assessing the costs of carbon reduction through a carbon tax or carbon permit system. Third, the module's technology and sectoral detail is sufficiently disaggregated to allow estimation of the cost of non-price policies (e.g., uniform performance standards) and price and non-price policies targeted to specific sectors or components of energy demand. The main disadvantages of this modeling framework include its complexity and its reduced-form treatment of input substitution, such as proper accounting and decision rules for investment in capital that has embodied energy requirements.

\subsection{Model Structure and Data}

The basic structure of the industrial module involves multiplying measures of industrial activity from the Annual Energy Outlook 1999 (AEO99) forecasts of industrial output by ratios of the quantity of each fuel consumed per unit of activity (i.e., energy intensity). These measures of energy-intensity are called Unit Energy Consumption (UEC) (e.g., KBtu of electricity/\$ output). UEC values are taken directly from the NEMS industrial module and are based on the MECS, consulting reports to EIA, and engineering judgment supplied to EIA. In most cases the UECs are adjusted over time to reflect changes in relative fuel prices (either in baseline EIA forecasts or caused by the implementation of a carbon tax) or to reflect technological change; in other cases the UECs are constant over the modeling horizon (the year 2010). See the NEMS documentation (EIA 1999) for detail on the model structure.

The model distinguishes and handles differently three types of industrial energy consumption: process and assembly (PA) (52 percent of industrial consumption); boilers, steam, and cogeneration (BSC) (40 percent); and buildings (BLD) (6 percent). The treatment of PA energy consumption differs for each industry depending on its broad class (e.g., energy-intensive vs. non-energy intensive manufacturing), but the treatment of BSC and BLD energy consumption is the same across industry classes. Thus, the inputs necessary from other NEMS 
modules (fuel prices, output, employment), the method used to adjust fuel shares for fuel price changes, and assumptions about technological change vary for different components of industrial energy demand.

Process and Assembly (PA). Almost all energy consumption in the non-manufacturing industry class is categorized as PA. Energy consumption for PA is found by multiplying UECs (KBtu/\$ output) by output for that industry, differentiated by industry and fuel. The nonmanufacturing UECs are only weakly adjusted for technology, allowing for a slow but steady decrease in energy intensity unrelated to price changes. There is also an adjustment of retirement rates based on average fuel prices across all fuels. Non-manufacturing energy use also contains a small amount of BSC from the combustion of biomass for cogeneration and steam production.

Baseline PA energy consumption for non-energy-intensive manufacturing is found by multiplying UECs (KBtu/\$ output) by output for that industry, differentiated by industry and fuel. Non-energy-intensive manufacturing fuel consumption is adjusted for changes in both relative and industry average fuel prices based on coefficients from NEMS which adjust both the rate of technological change and the rate of retirement of old capital. These effects do alter the fuel shares, but not by using explicit cross-price elasticities.

Baseline PA energy consumption for energy-intensive manufacturing is found by multiplying UECs (energy consumption/\$ or ton of output) by output for that industry, differentiated by fuel for specific processes or end-uses in each industry. When UECs are given per ton, assumed constant physical/value output ratios (ton/\$) are used for conversion (thus assuming a constant output price). Energy-intensive manufacturing fuel shares are adjusted for changes in relative fuel prices based on assumed parameters using a logit equation.

To account for technological change, energy-intensive manufacturing UECs are reduced at an exponential rate over time based on engineering judgement supplied to EIA regarding UECs for state-of-the-art and advanced technologies. The rate differs by process and for existing versus new industrial capacity (from 0 to 2.7 percent annually), and capacity is assumed to be retired at an exponential rate which is also a function of fuel prices and initial levels by industry (differentiated by industry based on Census data). This rate is also adjusted for changes in industry average fuel prices to account for price-induced innovation. The model also contains some allowance for idle capacity. We assume that each industry is endowed in the base year with some amount of idle capacity (based on the 1996 Survey of Plant Capacity). Subsequently, as industry demand (output) increases, this idle capacity is employed in production at a rate 
which is a function of the share of total capacity which is idle. Finally, the model allows for some non-specific improvements in fuel conservation which are a function of energy prices.

Boilers/Steam/Cogeneration (BSC). The BSC component computes energy consumption necessary to meet the steam demands of the PA and BLD components of the industrial sector based on UECs for steam generation. Steam generated from fuel available as a byproduct of industrial production is subtracted from total steam demand to determine the net demand for steam generation from purchased fuels. BSC purchased fuel shares (but not overall fuel consumption or production of electricity) are adjusted for changes in relative fuel prices using econometrically estimated parameters from a logit equation applied to EIA Form 867 data. The quantity of electricity cogenerated with steam is computed based on the estimated parameters of a log-linear equation that relates electricity to total steam generation. Cogenerated electricity is allocated on a percentage basis for own use or sale to grid based on EIA Form 867 data. This allocation is constant across industries, but is forecast to change slightly over time. There is no adjustment for technological change in the BSC component, except that industries are assumed to become more efficient at producing byproduct fuels over time, thus reducing the net steam demand.

Buildings (BLD). Building consumption is treated consistently in both manufacturing classes and is a mixed function of employment and output, differentiated by industry and fuel. Building UECs are not adjusted for non-forecast changes in fuel prices over time, and are not adjusted for technological change. Building consumption is calculated by multiplying UECs (KBtu/thousand employees and KBtu/\$ output) by the number of employees and the amount of output respectively. These values are then weighted and summed to calculate the total building energy use.

Data and Benchmarking. As detailed above, INSECT employs modeling structure assumptions, parameter values, and exogenous input variable projections from several sources including the NEMS documentation, AEO99, and other sources. The model structure and parameter values are primarily from the NEMS Industrial Module Documentation and personal communications with Crawford Honeycutt at EIA. Many exogenous input variable projections (i.e., output, baseline fuel price projections, carbon emission factors, electricity fuel shares) are from AEO99. Pre-1997 fuel prices are from the 1997 Annual Energy Review. Baseline regional capacity shares are from NEMS, the 1996 Survey of Manufacture, the 1992 Census of Agriculture, the 1992 Census of Construction, and the 1992 Census of Mineral Industries. Baseyear capacity utilization rates are from the 1996 Survey of Plant Capacity. Employment projection are from the 1996 Survey of Manufactures. The baseline results of the model are 
benchmarked to the results reported in AEO99 for 1994, differentiated by industrial sector and fuel. These benchmark factors are then multiplied by the results for all subsequent years and scenarios to calculate the final results of the model.

\subsection{Application of Carbon Policies}

The model is capable of computing any number of different carbon tax scenarios, as well as uniform standards. The taxes are levied on fuel use, and reflected in fuel prices. This implies that the tax is levied on fuel suppliers, but they are able to pass $100 \%$ of the tax onto their industrial consumers. The tax is assumed to be administered in terms of $\$ /$ metric ton of carbon. This is translated into \$/MMBtu of fuel, and is differentiated by fuel based on carbon content. ${ }^{11}$ The tax can be levied on all fuels together (a true carbon tax) or on individual fuels. Since the model does not contain foresight, to approximate the effects of foresight we levy the tax beginning in the year 2000. INSECT's technology and sectoral detail is also sufficiently disaggregated to allow estimation of the cost of non-price policies (e.g., uniform performance standards) and price and non-price policies targeted to specific sectors or components of energy demand.

Figure 4 illustrates our results for the costs of carbon mitigation for the industrial sector. The results show that for a "price" policy, based either on a carbon tax or tradable permit system, the marginal cost of carbon mitigation rises at an increasing rate, with a $5 \%$ reduction in emissions costing about $\$ 65 /$ ton. The "uniform percentage rollback" policy evaluates a series of percentage emissions reductions by industry group for manufacturing industries. Policy costs and emissions changes are calculated for each percentage level for each industry group. The resulting marginal cost curve for all of industry is higher than for the more efficient price policy-about $50 \%$ more expensive on the margin for a $5 \%$ reduction in emissions.

\footnotetext{
11 The emissions factors used for converting Btu's of energy consumption to carbon emissions were as follows, in MtC/QBtu: 49.3 for electricity (DOE 2001, pp. 128,151); 14.4 for natural gas ; 19.75 for distillate; 25.29 for steam coal; 21.28 for residual oil; 20.11 for other petroleum; 16.79 for LPG; 25.28 for coal/coke; and 19.16 for motor gasoline (EIA 2002, p. B-1).
} 


\section{Household Transportation Model}

\subsection{Overview}

The U.S. household transportation model developed by RFF for this project tracks stocks of vehicles from production to retirement, together with a vehicle use model that estimates annual vehicles miles traveled (VMT) for each type of vehicle (Harrington et al. 2003). The model is designed to investigate both short and long run household transportation responses to policies aimed at reducing carbon emissions. For example, in the short run, we would expect households to drive fewer miles in response to policies that increase the cost per mile where the magnitude of the reduction will depend on the elasticity of miles traveled with respect to price per mile. Over time, households will most likely respond to changing vehicle prices and fuel costs from carbon policies by altering the number and types of vehicles (i.e. new vehicle purchases). In fact, many argue that CAFE standards will not only change the relative prices of new vehicles by class, but could also change the relative prices of new and used cars (Kleit 1990; Kwoka 1983; Thorpe 1997). By decreasing driving cost, it has also been observed that higher fuel economy will lead to increased VMT, a phenomenon often called the "rebound effect."

The model includes vehicle production, household demand and use, and a scrappage market. Vehicle manufactures are assumed to choose endogenously the quantities and fuel economy of new cars and trucks. The cost of new vehicles is assumed to change based on changes in the fuel economy demanded by households in response to CAFE policies and fuel taxes. The scrappage market determines the supplies of used cars and we model an endogenous scrappage probability that is dependent on the mean value of old vehicles and an exogenous scrap value. Vehicle demand derives from a model of households that are assumed to choose the number and types of vehicles to own and the miles to drive them to maximize utility subject to a budget constraint.

\subsection{Model Structure and Data}

In this section, we describe the stylized simulation model of household vehicle stocks used to investigate the distributional and welfare effects of corporate fuel economy standards and fuel taxes over time. We assume for simplicity that new and used car and trucks represent the relevant class/vintage combinations and along with size and age, vehicles are distinguished by fuel economy. See Harrington et al. (2003) for a more detailed discussion of the model and data. 
Each period, households demand new and used cars based on the relative prices and operating costs, which is the gas price divided by miles per gallon. Automobile producers respond by producing new cars and trucks, where we assume that producers are price-takers and the production technology is constant returns to scale. We also simplify the cost function to focus on the cost of meeting increased corporate average fuel economy (CAFE) or demand for higher fuel efficiency by only allowing costs to vary depending on fuel economy. The baseline cost and fuel economy of each vehicle are the average price and fuel economy of new vehicles as found in the 1990 National Personal Transportation Survey. ${ }^{12}$ The supply functions for old vehicles are the scrappage functions, where the scrappage rate depends on the price of old vehicles and their scrap value. Overall, the fleet inventory model is similar to the model described in (Berkovec 1985), except that we update the cost of vehicle production to reflect the added costs of meeting CAFE standards (National Research Council 2002). Because of the data set used for demand estimation, it is convenient to think of the simulation as beginning in 1990. All costs are therefore in 1990 dollars.

The dynamics of the model follow from the carryover of vehicle stocks from one period to the next. For example, the stock of new cars and trucks in period T, become the stocks of used vehicles in period $\mathrm{T}+1$. Consumers and producers are assumed to respond only to conditions in the current period. New vehicles transition into old after being in the fleet over $3 \frac{1}{2}$ years. We also decompose the number of new vehicles of type $\mathrm{j}$ demanded in year $\mathrm{t}$ by 24 household types, defined by income, household size, and residence in an urban or rural area. ${ }^{13}$ The stock equations for old vehicles track the influx of the aging new car fleet and the outflow of vehicles lost to scrappage. Following Manski and Goldin(1983), the scrappage probability is assumed to follow an exponential distribution where in the simulations, we assume a constant scrap value for cars and trucks derived from Berkovec (1985).

\footnotetext{
12 The survey is a random sample of U.S. households that includes information on the make, model, and vintage (model year) of each vehicle in each household and the annual miles that each vehicle is driven. The NPTS also includes information on household income, age and education of household members, number and ages of children, work status of household members, and many others. The non-published parts of the NPTS provided additional information on distance to nearest transit station and zip code of respondents, which is used to link the data to local demographic information such as whether the household lives in a Metropolitan Statistical Area (MSA) of particular size.

13 The income categories are less than 20k, 20k-35k, 35k-50k, and greater than 50. Households are also broken up based on size (1,2, and greater than 2 household members) and whether it resides in a rural or urban area.
} 
In each period, the market equilibrates at the point where supply equals demand across the 4 vehicle stocks. Computing the equilibrium requires solving 12 nonlinear equations for 12 unknowns: 4 vehicle stocks, 4 vehicle prices, 2 new vehicle production quantities, and 2 new vehicle fuel-economy ratings. Given the assumption that producers are price takers, the supply of new vehicles will be at the point where price equals marginal cost. Because we assume infinitely elastic vehicle supply for new vehicles and that vehicle manufacturers are price takers, the initial vehicle costs are equal to initial-period prices. Therefore, in the model, any future increase in the price of vehicles is due to increases in mpg, which is equivalent to saying that the production costs across all other vehicle characteristics are held constant over time.

Expected aggregate household demand for new and old vehicles depends on the relative prices and operating costs, which is equal to the ratio of the gas price and the miles pre gallon in period $t$. The demand for each vehicle type is found by taking the expected demand for that vehicle summed over all household types, after scaling up the estimates to the population level based on the sample weights provided by the NPTS survey and the number of households in 1990. We estimate the probability that each household type will demand a certain number of vehicles of a given class/vintage based on expected utility theory. The estimation model is discussed in section 4.3 .

After solving for the market equilibrium in period $t$, we compute the expected vehicles miles traveled per car by household type h. There are potentially significant adjustment costs associated with household VMT responses to policies targeted at fuel use. For example, if there are large increases in fuel prices, households might respond first by eliminating non-essential trips, but if these increases are perceived to be permanent, over time the household might choose a residential location closer to work. This leads us to compute changes in VMT using a partial adjustment framework. The VMT submodel is based on expected VMT as predicted from our regressions of annual VMT on operating costs, household income, vehicle ownership, and residential location and household characteristics. Given the disaggregate nature of the model, we compute vehicle stock level estimates of vehicles miles traveled, changes in VMT per car, and changes in VMT for all U.S. households.

\subsection{Estimation}

Households are assumed to choose the number of vehicles to own and the miles to drive them to maximize utility subject to a budget constraint. The functional specification in the vehicles miles traveled estimation is consistent with the underlying preference structure in the 
utility function used in the estimation of vehicle choice and class/vintage. The household demand model is estimated using data from the 1990 Nationwide Personal Transportation Survey (NPTS). Our model structure closely resembles the models employed in Berkovec(1985), Mannering and Winston (1985), Train (1986), and Goldberg (1998) that are based on expected utility theory and estimated using discrete/continuous choice econometric techniques (Dubin and McFadden 1984). ${ }^{14}$ One difference with the previous literature is that we limit the number of class/vintages to four; new car, new truck, old car and old truck where the truck classification includes vans, pick-ups and sport utility vehicles. For several reasons we have simplified the class/vintage choice set considerably. Aggregation makes it easier to understand the dynamics of the model results and greatly reduces run times in both the econometrics and the simulation without, we believe, sacrificing any of the fundamental insights available from the model. The estimation results are presented in Harrington et. al. (2003).

\subsection{Carbon Policies}

The simulation model, as informed by the econometric estimation, is capable of analyzing a wide variety of fuel conservation policies, including CAFE, fuel taxes, gas guzzler taxes, and subsidies for more fuel-efficient vehicles. In running the simulations, our estimate of the "rebound effect" - the sensitivity of vehicle miles traveled (VMT) to changes in vehicle fuel economy - is 0.73 . This estimate is high compared to other results in the literature, for example, a recent survey by Greening et al. (2000) finds most estimates to be in the range 0.1 to 0.3 . Because the coefficients in the VMT equation appear to be driving this result, we apply a common adjustment factor to bring our estimate in line with the range found in Greening et al. (2000).

In Harrington et. al. (2003), we examine two types of policies: the tightening of the current CAFE standards (27.5 mpg for cars and 20.7 for trucks) and the use of taxes to raise the price of fuel. In particular, we allow a gradual increase in CAFE or fuel taxes over a ten year period, after which they are held constant at the tenth-year values. For CAFE, both the car

\footnotetext{
14 We estimate the model sequentially where we first estimate a nested multinomial logit model of the numbers of vehicles to own $(0,1,2$, or 3$)$ and the class/vintage of each car and then conditional on these choices; we estimate a model of vehicles miles traveled (Goldberg 1998; Train 1986). We also do not restrict the coefficients on the common variables to be equal across the choices. The estimation of vehicles miles traveled is linked to the vehicle choice results when the estimated probabilities of choosing a particular class/vintage are used to correct for sample selection bias that exists in an ordinary least squares regression of the VMT (Harrington et al. 2003).
} 
standard and the truck standard are raised at the same percentage rate. In these examples considered here we examine the effects five years after the ten-year period ends. We compare these instruments to a baseline in which there are no changes in the CAFE policy or the fuel tax for the entire 15-year period. The two policy instruments are calibrated to achieve two policy goals, a 10 and 20 percent fuel-use reduction compared to the beginning of the simulation, respectively, giving four different policy scenarios. The baseline itself results in a two percent reduction, so the reductions with and without the policy are 8 and 18 percent, respectively. The likely reason for this drift is that the fuel economy standards in place in 1990 had not been fully expressed in the vehicle fleet.

Achieving the 10 percent reduction in fuel use by the end of year 15, under the current assumption of a 0.1 rebound effect, would require an increase in CAFE standards of $20 \%$ and a gasoline price increase of $51 \%$. In the CAFE policy, the fleet is older, more fuel efficient, and (therefore) more expensive. All the reductions in fuel use are achieved by improvements in vehicular fuel economy, which is not surprising since CAFE policy effects the stock and not flow of services provided from a vehicle. Under the fuel tax policy, fuel use reductions are shared between improvements in fuel economy, reductions in vehicle use and, as the policy goal becomes more ambitious, reductions in the size of the fleet.

The two policies also differ substantially in their transitional effects and lag times before large changes in fuel use are experienced. For example, the CAFE policy requires complete fleet turnover. If we ran the CAFE policy out to reach a steady state, the reduction in fuel use would be about 16 percent, which is higher than the goal of 10 percent. On the other hand, households begin to respond immediately to fuel taxes, but the potential gain (reduction in fuel use) in the steady state is lower than the CAFE policy. As Harrington et al. (2003) illustrate, these dynamic effects are important factors in calculating the relative costs of the two policies.

\section{Discrete-Continuous Choice Model of Energy Demand}

\subsection{Model of fuel choice and energy demand}

We posit that building owners and developers face a two-stage decision process when they determine their energy demand for particular end uses (e.g., heating, water heating, cooking, miscellaneous, and other electricity). In the first stage, they choose which alternative fuel or combination of fuels to use for each end use, or perhaps they decide to use no fuel at all. Choice options for cooking, for example, include electricity, natural gas, and joint use of electricity and 
natural gas. We call this first stage the fuel choice decision-it is based on comparing the cost of each alternative, which will depend on fuel prices, equipment costs, and individual building characteristics. Conditional on the first stage, in the second stage, energy demand decision, managers determine how much of each fuel to use. Similar observed and unobserved variables influence these related discrete and continuous decisions, and care must be taken to correctly account for that relationship.

Our approach, based on Dubin and McFadden (1984), specifies that for a given end use, the cost $C_{i, j}$ of each option $i$ for building $j$ is

$$
C_{i, j}=f_{i}\left(p_{i, j}, r_{i, j}, \mathbf{Z}_{j}, s_{j}\right)+\varepsilon_{i, j},
$$

where $p_{i, j}$ is the price of energy, $\mathbf{Z}_{j}$ is a vector of building-specific characteristics (e.g., building type, size, age, climate), $s_{j}$ is a given desired level of building energy services, $r_{i, j}$ is the price of equipment, $f_{i}$ is a function relating these variables to total cost, and $\varepsilon_{i, j}$ is an independently and identically distributed random disturbance. In cases where the building only uses one fuel for each end use, $p_{i, j}$ is simply equal to the price of that fuel. In cases where multiple fuels are used for an end use, $p_{i, j}$ is a vector of prices of the utilized fuels.

The first-stage choice among alternative fuels or fuel combinations explains which fuel option is used based on weighing the relative costs of different options. Assuming the disturbances $\varepsilon_{i, j}$ have extreme value distributions with

$$
\operatorname{Pr}\left(\varepsilon_{i, j}<\varepsilon\right)=\exp (-\exp (-\varepsilon))
$$

the probability that option $i$ has the lowest cost and is therefore chosen is given by

$$
\operatorname{Pr}\left(\delta_{i, j}=1\right)=\frac{\exp \left(f_{i}\left(p_{i, j}, r_{i, j}, \mathbf{Z}_{j}, s_{j}\right)\right)}{\sum_{i^{\prime}} \exp \left(f_{i^{\prime}}\left(p_{i, j}, r_{i, j}, \mathbf{Z}_{j}, s_{j}\right)\right)},
$$

where $\delta_{i, j}$ is a dummy variable equal to one for the option $i$ selected by building $j$ and zero otherwise, and $i^{\prime}$ indexes all fuel choice options. A multinomial logit likelihood function can be formed based on Equation (3) and the parameters estimated using maximum likelihood.

The second stage explains the level of fuel use conditional on the fuel option chosen. Using Equation (2) coupled with Shephard's lemma, we can derive the demand for energy, $x$, by building $j$ with fuel option $i$ as 


$$
x_{i, j}=\frac{\partial C_{i, j}}{\partial p_{i, j}}=g_{i}\left(p_{i, j}, r_{i, j}, \mathbf{Z}_{j}, s_{j}, \eta_{i, j}\right)
$$

where $\eta_{i, j}$ is an error term. An important observation in the literature that we raised above is that the $\mathcal{E}$ s and $\eta$ 's are likely to be correlated. Unobserved characteristics that affect the demand for a particular fuel are likely to affect the costs — and thus the likelihood—of choosing that fuel option. Knowing, for example, that the natural gas option was chosen despite strong predictions to the contrary, suggests that perhaps the demand for natural gas will be different than the predicted value. In effect, there is an omitted variable related to fuel choice in the energy demand equation. As a consequence, the conditional expectation of $\eta_{i, j}$ is not zero (i.e., $\mathrm{E}\left[\eta_{i, j} \mid\right.$ $\left.\delta_{i, j}=1\right] \neq 0$ ), but rather is a function of the choice probability. This violates the standard OLS assumption that guarantees consistency, and is analogous to the sample selection problem discussed by Heckman (1979). Unless a "selectivity correction" is made, the estimated coefficients of the demand model will be biased. Assuming that $\eta_{i, j}$ is correlated with $\varepsilon_{i, j}$, but not the $\varepsilon_{i^{\prime} \neq i, j}$ (i.e, the choice errors for the options not chosen), Dubin and McFadden (1984) show that $\mathrm{E}\left[\eta_{i, j} \mid \delta_{i, j}=1\right]$ is proportional to $\ln \left(\operatorname{Pr}\left(\delta_{i, j}=1\right)\right)$. Thus, we can correct for the selection problem by including the log of a consistent estimate of the choice probability (i.e., the predicted probability from the estimated choice equation) as an additional explanatory variable in the energy demand equation, so that the remaining portion of the disturbance in Equation (4) has an expectation of zero.

\subsection{Econometric specification}

For each of the fuel choice options $i$, we assume the functional form for the fuel choice (5) equation is

$$
C_{i, j}=\beta_{i}+\boldsymbol{\beta}_{i, p} \cdot \ln \mathbf{P}_{j}+\frac{1}{2} \ln \mathbf{P}_{j} \cdot \boldsymbol{\beta}_{i, p p} \ln \mathbf{P}_{j}+\beta_{i, y} \ln y_{j}+\boldsymbol{\beta}_{i, p y} \cdot \ln \mathbf{P}_{j} \ln y_{j}+\boldsymbol{\beta}_{i, z} \cdot \mathbf{Z}_{j}+\varepsilon_{i j},
$$

where the $\beta$ are parameters and $\boldsymbol{\beta}$ are vectors of parameters, $\mathbf{P}_{j}$ is a vector of fuel prices, and we have broken out $y_{j}$, the size of building $j$, from the other building characteristics $\mathbf{Z}_{j}$, to allow for scale biases in fuel choice. Employing this functional form, we estimate the first stage fuel choice model given by Equation (3) as a maximum likelihood multinomial logit model (see Madalla (1983) for estimation details).

From the estimated choice model, we construct the selectivity correction for each option in each

building, $\hat{\lambda}_{i, j}$, which we subsequently include in the energy demand equation(s) for each option. 
Our estimation procedure for the energy demand model differs only slightly depending on whether the fuel choice option chosen involves a single fuel or multiple fuels. For single fuel options, we specify the energy demand equation for each fuel choice option as

$$
\ln x_{i, j}=\gamma_{i}+\gamma_{i, p} \cdot \ln p_{i, j}+\gamma_{i, y} \ln y_{j}+\gamma_{i, z} \cdot \mathbf{Z}_{j}+\gamma_{i, \lambda} \hat{\lambda}_{i, j}+\mu_{i, j}
$$

where the $\gamma$ are parameters and $\gamma$ are vectors of parameters, $\hat{\lambda}_{i, j}$ is the selectivity correction term from the fuel choice equation, and $\mu_{i, j}$ is an iid random disturbance specific to each option and building. ${ }^{15}$ For fuel choice options involving combinations of more than one fuel, we simultaneously estimate two equations of the form (6), and include the prices of both fuels in each demand equation. ${ }^{16}$ We therefore estimate a total of 5 logit choice equations (with a total of 20 choices) and 28 demand equations ( 1 demand equation for electricity-only end uses, 12 for heating, 6 for water heating, 5 for miscellaneous end uses, and 4 for cooking). These equations contain a total of several hundred parameter estimates.

Simple aggregate model. For comparison purposes, we also estimate a simplified model that estimates aggregate energy use by fuel, and does not treat the fuel choice decision or estimate separately by end use. The four equations (electricity, natural gas, fuel oil, district services) are of the form (6), except that $\hat{\lambda}_{i, j}$ is not included and all fuel prices are included in each fuel demand equation.

\subsection{Commercial Buildings Energy Consumption Survey}

The data for this study come from the 1995 Commercial Buildings Energy Consumption Survey (CBECS) conducted by the United States Energy Information Administration (EIA) (EIA 1998). CBECS is a quadrennial (previously triennial) survey of commercial buildings in the United States, which are defined to include buildings used by the service sector which includes

\footnotetext{
15 Note that we do not impose the functional form or cross equation parameter restrictions that are implied by the structural relationship between Equations (2) and (4), namely that the demand function is a derivative of the cost function. In moving toward empirical estimation, one must be careful in placing too much structural restriction on the econometric relationship of the equations for fuel choice, energy demand, and fuel share in part because the decisions may occur at different times under different conditions. Any such structural relationship is also complicated by the discrete choice nature of the first stage choice model, which estimates choice probabilities rather than directly estimating the parameters of the cost function.

16 Note that unlike share equations or unlogged demand equations, there is no automatic restriction on the crossprice elasticities.
} 
wholesale and retail stores, hotels, and hospitals as well as other institutions such as churches and schools. The 1995 survey results include observations for 5,766 buildings sampled to represent about 4.6 million commercial buildings and 59 billion square feet of floorspace. The dependent variables are based on KBtus of each of four fuels (electricity, natural gas, fuel oil, and district heat) consumed in each building, by each of five end uses (heating, water heating, cooking, miscellaneous, and other end uses that use only electricity (lighting, cooling, office equipment, refrigeration, ventilation)). Table 5 shows fuel expenditure shares by end use and fuel type. Electricity-only end uses alone account for about $80 \%$ of expenditures, with natural gas accounting for most of the remainder.

Table 5 provides descriptive statistics on the explanatory variables. The explanatory variables include: fuel prices; percent heated and cooled; number or workers; hours open weekly; temperature (cooling and heating degree days); whether building is owner-occupied; size (square feet); number of floors; age (in 20-yr intervals); location (North, South, Midwest, West); whether building is in part of a multi-building facility; whether building has a central physical plant; and the type of building (restaurant, warehouse, hospital, public, lodging, retail, or other). All explanatory variables were included in all equations in the form given by equations (5) and (6), with all non-percentage continuous variables first being logged. Percent lit was also included in equations for the electricity-only end use. Other potentially relevant variables available in the CBECS data were excluded either because there were many missing observations or because the variable was estimated to have negligible effect.

\subsection{Estimation and simulation}

Data imputation. Perhaps the most vexing problem that we face is a rather extensive amount of missing data, in particular price information for the fuel choice equations. Prices are derived from the ratio of fuel expenditures to fuel quantity. When a fuel is not used by a particular facility, for any end use, the price is not observed. We are also missing data on the percentage of building cooled, percentage of building heated, percentage building lighted, whether the building is owner-occupied, number of hours the building is open weekly, number of workers in the building, and cooling degree days.

To address missing data, we use a multiple imputation approach (Rubin 1987). We estimate a relationship between each missing variable and other observed variables using a simple linear model based on complete observations. We then impute values for missing variables based on the predictions of the linear model plus a random disturbance based on the 
estimated error in the linear model. ${ }^{17}$ We repeat this imputation process five times, with different random disturbances for each imputation. Our analysis is performed on all five imputed data sets, with overall parameter estimates based on the average estimate across the five imputations and overall parameter variance estimates based on the sum of between and within variation measured in the five parameter estimates. ${ }^{18}$

Multinomial logit choice options. Once we have a complete (imputed) data set, we can implement the two-step discrete choice/linear demand model outlined in the text to estimate model parameters and simulate demand response. We do this for each of five end uses: heating, water heating, cooking, miscellaneous, and other electrical (miscellaneous includes nonexclusively electrical end uses). Several practical issues arise that require some attention as we estimate the model. The first is the number of choices in the discrete-choice step. There are four main fuels that account for the vast majority of all reported commercial energy use: electricity, natural gas, fuel oil, and district heat. Because these fuels substitute for one another, their use needs to be considered jointly, giving rise to a total of sixteen combinations.

Estimating a choice model with sixteen options, especially when some options are particularly uncommon, is impractical. In our work, we identify eight combinations that occur frequently enough to warrant inclusion and for most end uses we consider a smaller subset. Table 5 shows the pattern of fuel use combinations by end use. Observations that do not fit into our groupings are not used to estimate the model, but are used to predict fuel use and demand response to price changes. After estimating the fuel choice model, we use it to predict the probability of each possible fuel combination for each observation, including those observations that were ignored in the estimation based on their use of an unusual fuel combinations. ${ }^{19}$ We do this for both the benchmark prices as well as simulated price changes.

\footnotetext{
17 When we use the imputed price of district heat to estimate the fuel choice model (3), we inflate the imputed price by a factor of 10 for a randomly chosen $90 \%$ of the imputed observations. This helps us account for the fact that the use of district heat in most locations that do not already use district would likely involve very high fixed installation and access costs.

18 That is, if our estimates of a parameter $\theta$ equal $\theta_{1}, \theta_{2}, \theta_{3}, \theta_{4}$, and $\theta_{5}$, with variance estimates of $\sigma_{1}{ }^{2}, \sigma_{2}{ }^{2}, \sigma_{3}{ }^{2}, \sigma_{4}{ }^{2}$, and $\sigma_{5}^{2}$, across the five imputed data sets, the overall parameter estimate would be $\bar{\theta}=\left(\theta_{1}+\theta_{2}+\theta_{3}+\theta_{4}+\theta_{5}\right) / 5$ and the overall parameter variance estimate would be $\left(\sigma_{1}{ }^{2}+\sigma_{2}{ }^{2}+\sigma_{3}{ }^{2}+\sigma_{4}{ }^{2}+\sigma_{5}{ }^{2}\right) / 25+\left(\theta_{1}{ }^{2}+\theta_{2}{ }^{2}+\theta_{3}{ }^{2}+\theta_{4}{ }^{2}+\right.$ $\left.\theta_{5}^{2}\right) / 25-\bar{\theta}^{2} / 5$.

${ }^{19}$ For example, an observation that claimed to use fuel oil for cooking would be ignored in the estimation but we would still go back and predict the probability that this observation alternately used electricity, natural gas, or both (the three fuel combinations included in the estimation).
} 
Sampling weights in estimation. Another problem we confront is our desire to use the model to predict changes in aggregate fuel use for the commercial building sector. This requires use of sampling weights provided with the data set that indicate how many buildings each observation represents in the population. In order to compute aggregate energy demand, for example, the energy use of each building is multiplied by the weight, and then added up.

Because the sampling weights do not indicate anything about the variance of the error associated with a particular observation, weighted regression is not required to efficiently estimate the true model. In fact, any weighting will make the estimation inefficient. However, if the model is not exactly right, estimates using the unweighted sample will be more biased estimates of the population than if observations with higher sample weights were more heavily weighted. The solution is to compute the parameter estimates using the sample weights as if they reflected greater precision, but to compute the standard errors as if they did not. ${ }^{20}$

Another way to say this is that if you have two observations, one drawn from a pool of one hundred units and other drawn from a pool of ten, your best bet for the average across all one hundred and ten units is the simple mean - if you are sure the two pools are the same. If you are not sure they are the same, the best bet is an average that weights the observation from the larger pool more-ten times more. When computing the variance of this mean, however, you need to remember that while you weighted the observations to compute the mean, that has nothing to do with your opinion about the likely error in each observation, so that variance estimates should not be weighted. We follow this weighted estimation approach in our estimation of both the fuel choice and energy demand equations.

Sampling weights in aggregate prediction. After estimating the fuel demand equations for each fuel choice combination based on the observations that actually chose that fuel choice, we predict the fuel demand for all observations for all fuel choice combinations for both benchmark prices and simulated price changes. This raises an issue as we shift from predictions of $\log$ energy demand (the form in our model in (6)) to level energy demand. The issue is that meanzero predictions of log energy demand do not translate into mean-zero predictions of level energy demand because exponentiation is a non-linear function and non-linear functions generally do not preserve expectations. Mathematically, we have

\footnotetext{
${ }^{20}$ It would be unusual to presume that the regression model might be wrong without assuming the assumption of homoscedasticity might also be wrong. We therefore estimate the model with robust standard errors (White 1980).
} 


$$
E[y]=E[\hat{y}+e]=\hat{y}
$$

where $y$ is the true log energy demand, $\hat{y}$ is the predicted value in logs, and $e$ is the prediction error. But,

$$
E[\exp y]=E[\exp (\hat{y}+e)]=\exp \hat{y} \cdot E[\exp e] \neq \exp \hat{y}
$$

because $E[\exp e] \neq 1$. Assuming a normal distribution for $e$, one can compute $E[\exp e]=\exp \hat{\sigma}^{2} / 2$ where $\hat{\sigma}^{2}$ is the estimated variance of $e$ (see Goldberger 1968).

We actually take a slightly different approach incorporating the sampling weights so that our aggregate prediction matches actual aggregate energy use when the individual predictions are aggregated (analogous to the mean-zero error property of a linear model). That is, we want to ensure that

$$
\sum_{i} w_{i} \cdot E[\exp e] \exp \hat{y}_{i}=\sum_{i} w_{i} \exp y_{i}
$$

where again $y$ is the true log energy demand (for the observed data) and $w$ are the sampling weights, and at the same time provide a consistent estimator of exp $e$. The following consistent estimator of $\exp e$ satisfies this goal:

$$
E[\exp e]=\frac{\sum_{i} w_{i} \exp \hat{y}_{i} \cdot \exp e_{i}}{\sum_{i} w_{i} \exp \hat{y}_{i}},
$$

which in effect weights using both the sample weights and the predicted level of energy use. ${ }^{21}$ Once we calculate $E[\exp e]$, we scale up all of our predictions exp $\hat{y}$ of levelized fuel demand by this value for each end-use, fuel combination, and fuel. We compute estimates of expenditure by multiplying by price. The advantage of this approach is that we maintain the benchmark prediction of aggregate energy demand for the estimated sample when the sample is aggregated.

Once we have computed the level (unlogged) fuel use (and expenditure) predictions for each observation, end-use, fuel combination and fuel, we aggregate by computing

$$
\sum_{i, j, k} w_{i} \hat{p}_{i, j, k} \exp \hat{y}_{i, j, k, l} E\left[\exp e_{i, j, k, l} \mid j, k, l\right]
$$

\footnotetext{
${ }^{21}$ Note that any weighted average of observed values provides a consistent estimate of $E[\exp e]$, provided the sum of the squared weights, divided by the sum of the weights squared, is tending to zero.
} 
where $w_{i}$ is the sampling weight for observation $i, \hat{p}_{i, j, k}$ is the probability of the $k$ th fuel combination, for the $j$ th end use, and observation $i, \hat{y}_{i, j, k, l}$ is predicted log fuel demand for observation $i$, end use $j$, fuel combination $k$, and fuel $l$, and $e_{i, j, k, l}$ is similarly the error in the prediction of $\log$ fuel demand for observation $i$, end use $j$, fuel combination $k$, and fuel $l$. This delivers estimates of aggregate fuel demand for fuel $l$ across all commercial buildings for both the benchmark and the simulated price changes. Note that alternatively, we can also compute

$$
\sum_{i, j, k} w_{i} 1\left(k=Z_{i, j}\right) \exp \hat{y}_{i, j, k, l} E\left[\exp e_{i, j, k, l} \mid j, k, l\right]
$$

where $k$ is a particular fuel choice combination, $Z_{i, j}$ is the observed fuel combination choice for observation $i$ and end use $j$. This represents the predicted energy demand holding the choice of fuel combination fixed. Based on our weighting to compute $E[\exp e]$, we would exactly match the benchmark aggregate fuel use estimates for the sample, except we do not predict energy demand for certain fuel choice combinations that are observed in the sample. Nonetheless, this is still an interesting calculation for the sample as it portrays a short- to medium-term response where the choice of fuels may be fixed by capital investments.

Carbon price/tax simulations. We simulate the effect of carbon taxes (or equivalent permit system prices) on commercial energy demand and carbon emissions using parameter estimates from the fuel choice and demand models described above. We assess carbon taxes ranging from $\$ 10$ per metric ton of carbon $(\$ / \mathrm{MtC})$ to $\$ 150 / \mathrm{MtC}$ by increasing all fuel prices simultaneously based on the carbon content of each fuel, ${ }^{22}$ and assuming these increases are passed on to building occupants. We do not adjust the carbon content of electricity under carbon tax scenarios (due to fuel-switching), so that our results are best thought of as partial equilibrium in nature. ${ }^{23}$ For comparison to other studies and for other modeling efforts, we also compute demand elasticities by fuel type based on demand responses to simulated price increases, where fuel prices are altered one at a time. We report average elasticities for price increases resulting from a $\$ 50 / \mathrm{MtC}$ carbon tax.

\footnotetext{
22 The emissions factors used for converting Btu's of energy consumption to carbon emissions were as follows, in MtC/QBtu: 49.2 for electricity (EIA 2000, pp. 128,151); 14.47 for natural gas (EIA 2002, p. B-1); 19.95 for fuel oil (EIA 2002, p. B-1); and 38.36 for district heat. The district heat emissions factor was based on the portion of primary fuels used in district heat combustion (50\% natural gas; 18\% electricity; 27\% coal; and 5\% fuel oil (EIA 1993, p. 29), using an emission factor for coal of $26 \mathrm{MtC} / \mathrm{Qbtu}$ (EIA 2002, p. B-1) and a heat input-output ratio of 1.59 (EIA 1993).

23 Our estimates also hold constant the level of building services, although EIA general equilibrium analyses suggest such output effects in the commercial building sector would be negligible.
} 
Table 1: Description of Production Sectors

Aggregate Sector

Industry

Transportation Equipment

Services

Buildings

Household Transportation

Services

Electricity

Coal

Petroleum

Natural Gas
Composition (I-O industry number)

agriculture, forestry and fisheries (01-04); mining except coal (05-

06; 08-10); manufacturing except petroleum refining, motor vehicles, air and water transportation (11-30; 31 except 310101;

32-58; 62-64; 650100; 650200; 650301).

motor vehicles, aircraft and other transportation (59-61)

transportation and communications (650400-650702; 66-67);

water supply and sanitary systems (680301-680302)**; finance,

insurance, real estate except owner-occupied dwellings (70-71

except 7101); services except those listed under buildings (72-

73 except 7201; 75-77 except 76101, 760202, 760203, 7702,

770301, 7704; 78 except 7802; 79 except 7902; 81; 84)

warehousing and storage (650302); wholesale and retail trade (69);

owner-occupied dwellings (7101); hotels and lodging places

(7201); eating and drinking places (74); motion picture services and theaters (760101); bowling centers (760202); professional sports clubs and promoters (760203); private and public hospitals, nursing and personal care facilities (7702;770301;9910C1*;9910C2*); private and public educational services $(7704 ; 98 *)$

(created from household demand for petroleum, automotive repair shops and services, and household capital)

electric services (6801); federal electric utilities (7802); state and local electric utilities (7902), district heating**

coal mining (07)

petroleum refining (310101)

gas production and distribution (6802)

*These sectors were reclassified from government final demand.

**Commercial building district heat was reclassified from services to electricity. 
Table 2: 1992 Benchmark United States Social Accounting Matrix (\$1992 millions)

\begin{tabular}{|c|c|c|c|c|c|c|c|c|c|c|c|c|c|c|c|c|c|c|}
\hline \multirow[b]{3}{*}{ INDUST } & \multirow{3}{*}{\begin{tabular}{|l} 
INDUST \\
$1,407,460$
\end{tabular}} & \multicolumn{9}{|c|}{ Industry Demand } & \multicolumn{8}{|c|}{ Final Demand } \\
\hline & & TRANSEQ & SERVICE & BLDGS & ELECT & COAL & PETRO & GAS & GOVIND & TRANS & IVA & CONS & INVEST & INVENT & GOV & EXPORTS & IMPORTS & Total \\
\hline & & 119,792 & 239,197 & 296,687 & 31,312 & 4,121 & 78,901 & 45,872 & 0 & 4,296 & 0 & 774,438 & 604,872 & 16,155 & 234,216 & 298,415 & $-439,775$ & $3,715,960$ \\
\hline TRANSEQ & 8,847 & 74,637 & 23,240 & 6,575 & 72 & 41 & 146 & 90 & 0 & 3 & 0 & 121,333 & 97,718 & $-7,246$ & 54,700 & 76,397 & $-93,841$ & 362,713 \\
\hline SERVICE & 360,302 & 30,934 & 749,701 & 414,650 & 18,654 & 1,764 & 11,392 & 6,145 & 0 & 37,643 & 0 & $1,370,386$ & 24,775 & 1,671 & 98,295 & 97,684 & $-13,217$ & $3,210,779$ \\
\hline BLDGS & 241,295 & 25,816 & 77,284 & 77,038 & 3,297 & 1,098 & 5,478 & 905 & 0 & 18 & 0 & $1,776,607$ & 62,380 & 2,652 & 400,479 & 50,113 & 17,688 & $2,742,148$ \\
\hline ELECT & 40,643 & 2,163 & 64,895 & 37,797 & 32 & 586 & 1,410 & 195 & 0 & 6 & 0 & 79,548 & 4 & 0 & 9,258 & 282 & -697 & 236,121 \\
\hline COAL & 2,943 & 60 & 0 & 75 & 17,703 & 3,041 & 6 & 0 & 0 & 0 & 0 & 69 & 0 & 0 & 33 & 3,122 & -134 & 26,917 \\
\hline PETRO & 30,045 & 781 & 19,490 & 12,821 & 3,361 & 405 & 8,225 & 420 & 0 & 42,711 & 0 & 6,489 & 1,239 & 172 & 8,936 & 8,736 & $-11,551$ & 132,281 \\
\hline GAS & 15,946 & 467 & 4,392 & 6,807 & 6,853 & 34 & 11,076 & 17,098 & 0 & 2 & 0 & 28,639 & 1 & 11 & 1,295 & 536 & -1 & 93,157 \\
\hline GOVIND & 0 & 0 & 0 & 325,099 & 0 & 0 & 0 & 0 & 0 & 0 & 0 & 0 & 0 & 0 & 439,290 & 0 & 0 & 764,389 \\
\hline TRANS & $=0$ & $=0$ & $0=$ & $=0$ & $==$ & $=0$ & 0 & $=0$ & $=0$ & $=0$ & $=0$ & $=228,247$ & $==0$ & $=0$ & $=0$ & $=0$ & $==0$ & $=228,247$ \\
\hline IVA & 0 & 0 & 0 & 0 & 0 & 0 & 0 & 0 & 0 & 0 & 0 & 0 & 0 & $-7,982$ & 0 & 0 & 0 & $-7,982$ \\
\hline NCIMP & 13,008 & 968 & 25,965 & 4,601 & 31 & 23 & 310 & 58 & 0 & 0 & 0 & 33,009 & 0 & 0 & 12,063 & 0 & $-90,036$ & 0 \\
\hline K & 568,540 & 19,849 & 739,622 & 525,407 & 105,347 & 5,009 & 5,092 & 12,207 & 110,181 & 143,567 & $-7,982$ & 0 & 0 & 0 & 0 & 0 & 0 & $2,226,839$ \\
\hline $\mathrm{L}$ & 976,032 & 84,995 & $1,112,898$ & 762,240 & 34,099 & 8,366 & 6,367 & 5,837 & 654,208 & 0 & 0 & 0 & 0 & 0 & 0 & 0 & 0 & $3,645,042$ \\
\hline IBT & 50,899 & 2,250 & 154,095 & 272,352 & 15,360 & 2,429 & 3,877 & 4,329 & 0 & 0 & 0 & 0 & 0 & 0 & 0 & 0 & 0 & 505,591 \\
\hline ROW & 0 & 0 & 0 & 0 & 0 & 0 & 0 & 0 & 0 & 0 & 0 & $-66,481$ & 0 & 0 & -770 & 67,325 & -74 & $\underline{0}$ \\
\hline Total & $3,715,960$ & 362,713 & $3,210,779$ & $2,742,148$ & 236,121 & 26,917 & 132,281 & 93,157 & 764,389 & 228,247 & $-7,982$ & $4,352,284$ & 790,989 & 5,433 & $1,257,794$ & 602,609 & $-631,637$ & || $17,882,202$ \\
\hline
\end{tabular}


Table 3: Elasticities Estimated from Detailed Sectoral Models

\begin{tabular}{|l|l|l|}
\hline & KLEM elasticity & Energy elasticity \\
\hline Electricity sector & 0.10 & 0.00 \\
\hline Industry sector & 0.15 & 0.30 \\
\hline Buildings sector & 1.28 & 1.22 \\
\hline Transportation sector & 0.23 & 0.00 \\
\hline
\end{tabular}

*The elasticity between household transportation and consumption of other market goods, also estimated from the detailed transportation model, is 1.08 . 
Table 4: Ad Valorem Taxes and Subsidies Used to Simulate Inefficent Policies

\begin{tabular}{|l|l|l|l|}
\hline & CAFE & regional electricity & industry uniform stan. \\
\hline coal & & 0.126 & 0.122 \\
\hline oil & 0.342 & 0.012 & 0.013 \\
\hline natural gas & & 0.060 & 0.026 \\
\hline electricity & & & 0.045 \\
\hline capital & & -0.019 & \\
\hline labor and materials & -0.563 & -0.013 & -0.001 \\
\hline productivity & 0.000 & 0.000 & 0.000 \\
\hline & & & \\
\hline
\end{tabular}


Table 5: Descriptive Statistics

\begin{tabular}{|c|c|c|c|}
\hline Variable & $\begin{array}{c}\text { Number of } \\
\text { observations }\end{array}$ & Mean & Standard deviation \\
\hline Electricity price $(\varnothing / \mathrm{Kbtu})$ & 5,609 & 2.60 & 1.30 \\
\hline Natural gas price $(\varnothing / \mathrm{Kbtu})$ & 3,708 & 0.59 & 0.32 \\
\hline Fuel oil price $(\varnothing /$ Kbtu $)$ & 878 & 0.57 & 0.14 \\
\hline District serv. price ( $\phi / \mathrm{Kbtu})$ & 583 & 0.72 & 0.30 \\
\hline Percent heated & 5,369 & 0.89 & 0.25 \\
\hline Percent cooled & 4,947 & 0.74 & 0.34 \\
\hline Percent lit & 5,575 & 0.89 & 0.23 \\
\hline Number of workers & 5,472 & 244 & 959 \\
\hline Hours open weekly & 5,646 & 79 & 48 \\
\hline Cooling degree days & 5,755 & 1,312 & 879 \\
\hline Heating degree days & 5,766 & 4,357 & 2,249 \\
\hline Owner occupied $(0 / 1)$ & 5,653 & 0.79 & 0.41 \\
\hline Square footage & 5,766 & 127,606 & 265,892 \\
\hline Number of floors & 5,766 & 3.86 & 6.98 \\
\hline Age $\leq 20(0 / 1)$ & 5,766 & 0.41 & 0.49 \\
\hline $20<$ Age $\leq 40(0 / 1)$ & 5,766 & 0.34 & 0.47 \\
\hline $40<$ Age $\leq 60(0 / 1)$ & 5,766 & 0.12 & 0.33 \\
\hline $60<$ Age $\leq 80(0 / 1)$ & 5,766 & 0.07 & 0.25 \\
\hline $80<\operatorname{Age}(0 / 1)$ & 5,766 & 0.05 & 0.22 \\
\hline Northern U.S. (0/1) & 5,766 & 0.17 & 0.37 \\
\hline Southern U.S. (0/1) & 5,766 & 0.36 & 0.48 \\
\hline Midwestern U.S. (0/1) & 5,766 & 0.24 & 0.43 \\
\hline Western U.S. $(0 / 1)$ & 5,766 & 0.24 & 0.42 \\
\hline Multi-building facility $(0 / 1)$ & 5,766 & 0.43 & 0.50 \\
\hline Central physical plant $(0 / 1)$ & 5,766 & 0.13 & 0.34 \\
\hline \multicolumn{4}{|l|}{ Building type } \\
\hline Restaurant $(0 / 1)$ & 5,766 & 0.02 & 0.15 \\
\hline Warehouse $(0 / 1)$ & 5,766 & 0.14 & 0.35 \\
\hline Hospital (0/1) & 5,766 & 0.04 & 0.19 \\
\hline Public $(0 / 1)$ & 5,766 & 0.23 & 0.42 \\
\hline Lodging $(0 / 1)$ & 5,766 & 0.07 & 0.25 \\
\hline Retail $(0 / 1)$ & 5,766 & 0.20 & 0.40 \\
\hline Other type $(0 / 1)$ & 5,766 & 0.31 & 0.46 \\
\hline
\end{tabular}


Table 6. Expenditure Shares by End Use and Fuel

\begin{tabular}{|c|c|c|c|c|c|}
\hline \multirow{2}{*}{ End use } & \multicolumn{4}{|c|}{ Fuel } & \multirow{2}{*}{ Total } \\
\hline & Electricity & Natural Gas & Fuel Oil & District Services & \\
\hline Electricity only & 1.00 & & & & 0.84 \\
\hline Lighting & 1.00 & & & & 0.37 \\
\hline Cooling & 0.99 & & & & 0.11 \\
\hline Office equipment & 1.00 & & & & 0.10 \\
\hline Refrigeration & 1.00 & & & & 0.06 \\
\hline Ventilation & 1.00 & & & & 0.05 \\
\hline Heating & 0.24 & 0.50 & 0.08 & 0.19 & 0.15 \\
\hline Miscellaneous & 0.88 & 0.10 & 0.02 & & 0.07 \\
\hline Water heating & 0.22 & 0.50 & 0.06 & 0.23 & 0.07 \\
\hline Cooking & 0.29 & 0.71 & & & 0.02 \\
\hline Total & 0.81 & 0.13 & 0.02 & 0.04 & 1.00 \\
\hline
\end{tabular}


Figure 1: Production Sectors in the General Equilibrium Model

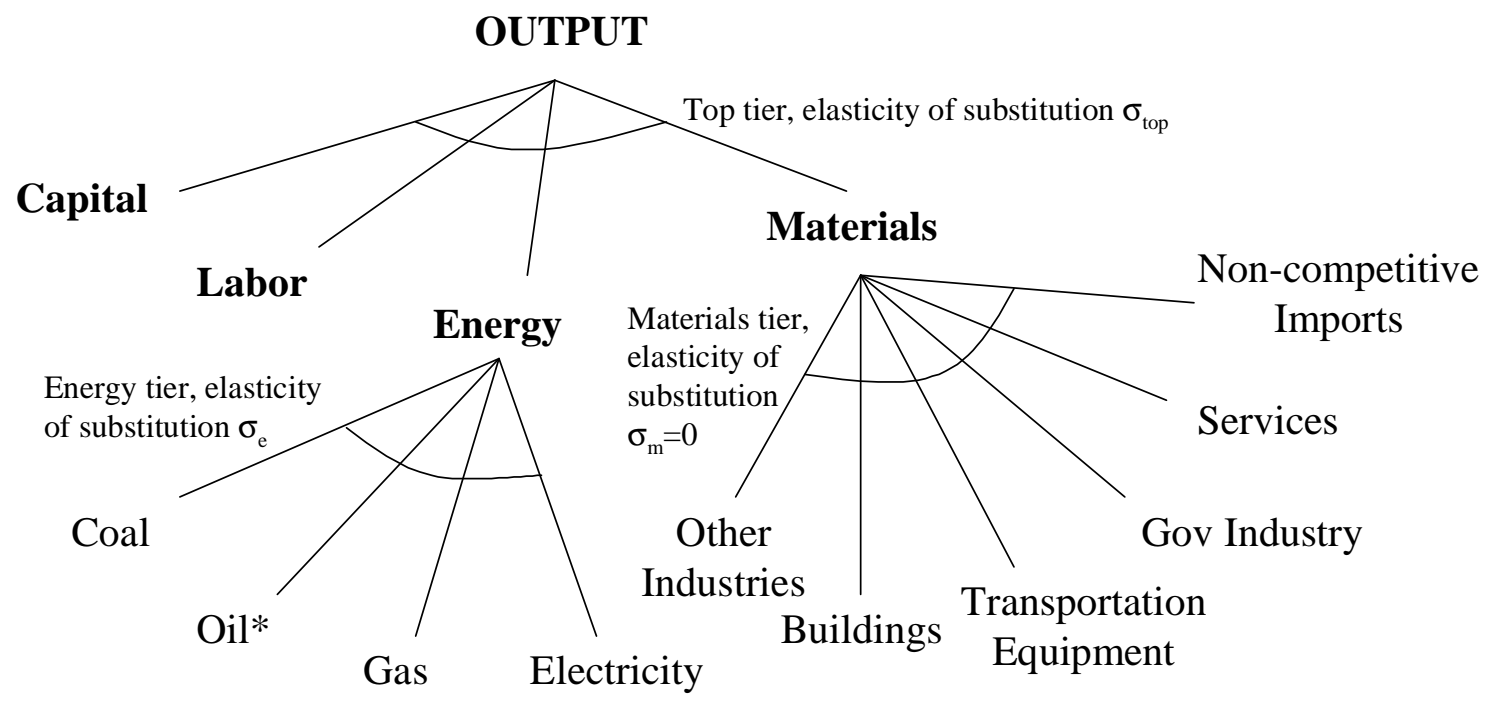

* Oil is included in the materials tier for the household transportation services sector to allow fuel and fuel delivery services to be combined in a sub-tier before combining with capital in the top tier. 


\section{Figure 2: Nesting of Aggregate Consumption Good}

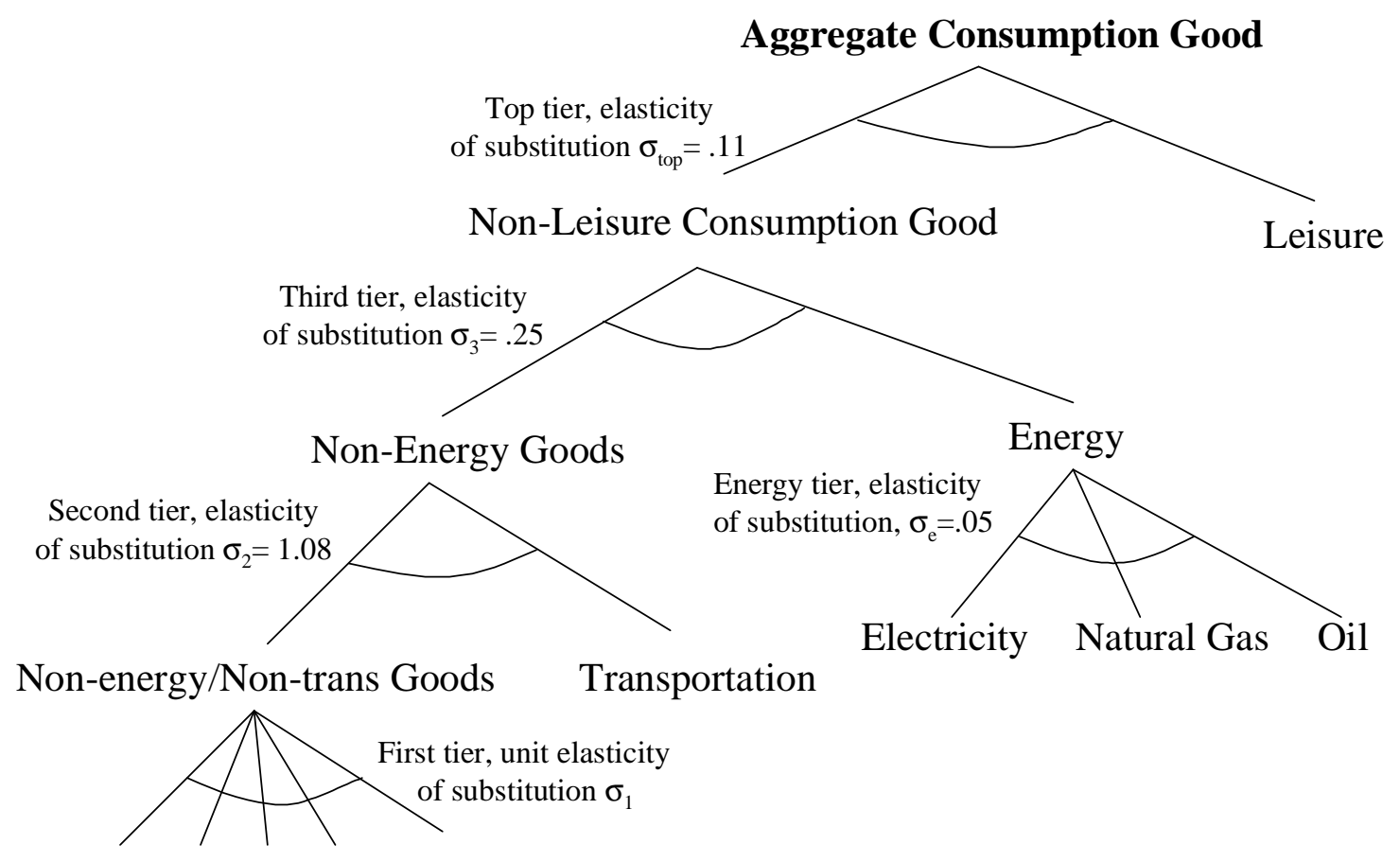

Non-energy/Non-transportation Goods 
Figure 3: Comparison of Emission Reduction Schedules for Reduced-form and Detailed Sectoral Models
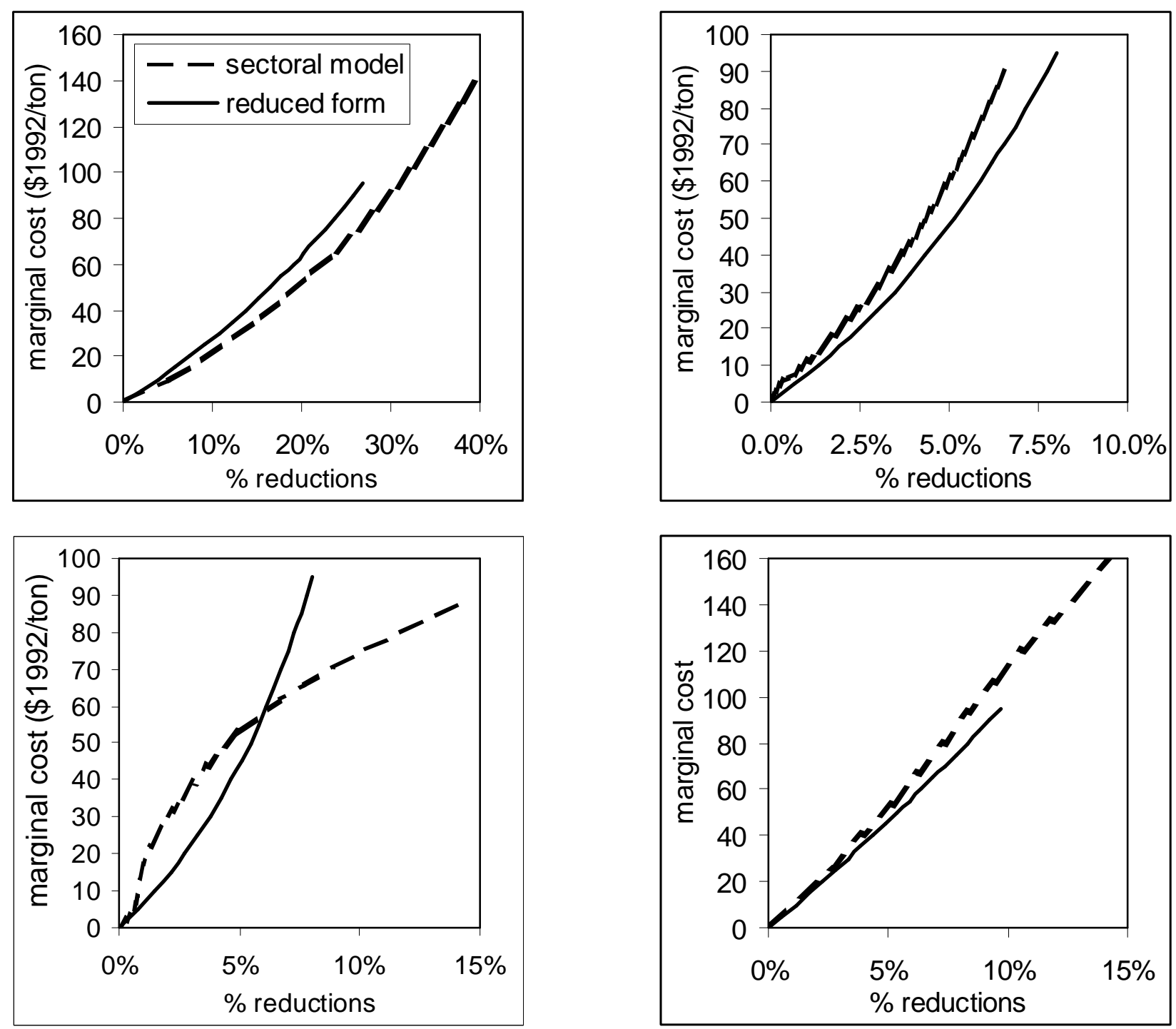


\section{Figure 4}

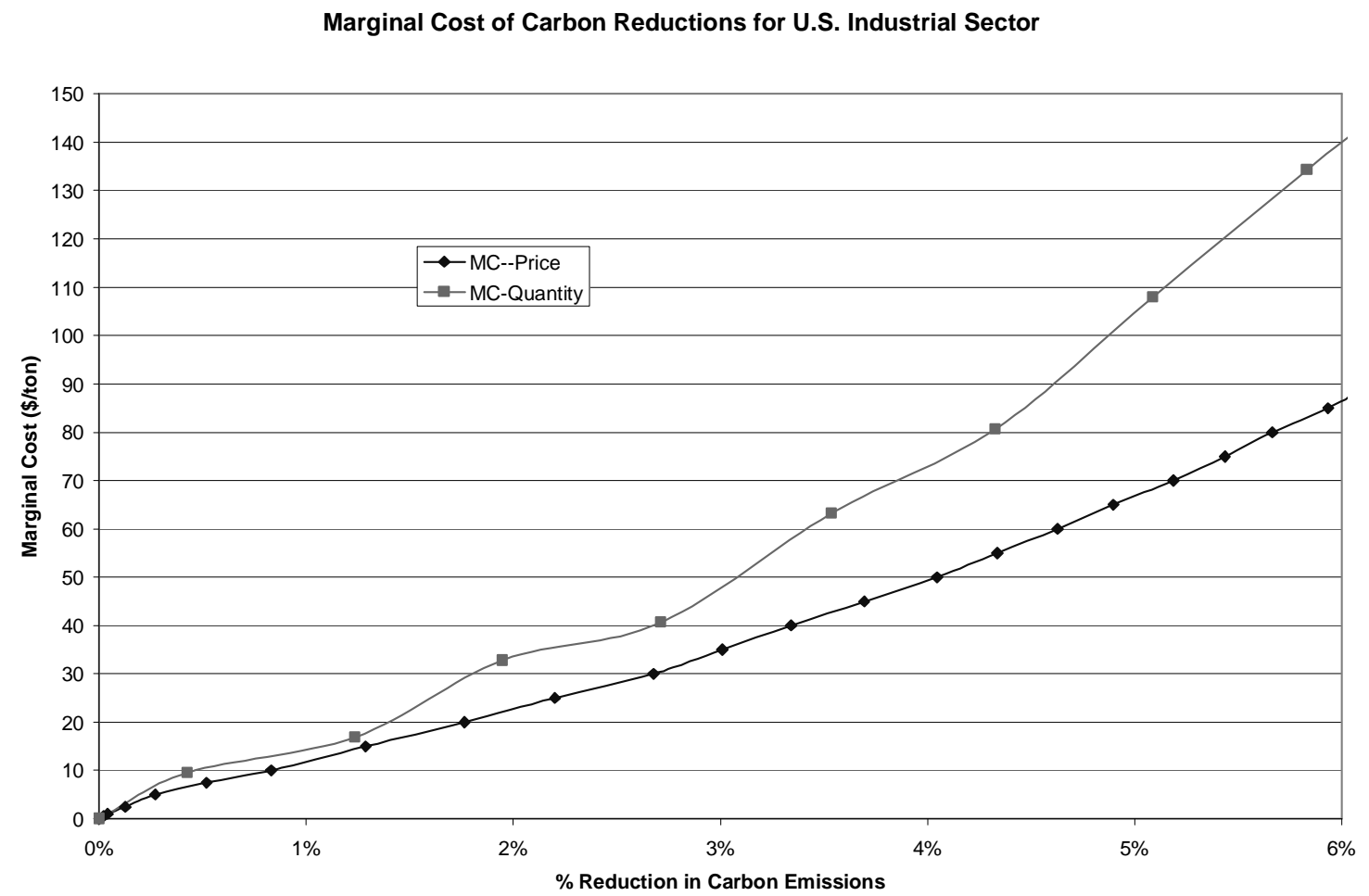




\section{References}

Ballard, Charles L., Don Fullerton, John B. Shoven, and John Whalley. 1985. A General Equilibrium Model for Tax Policy Evaluation. Chicago: University of Chicago Press.

Berkovec, James. 1985. New Car Sales and Used Car Stocks: A Model of the Automobile Market. Rand Journal of Economics 16 (2):195-214.

Bureau of Economic Analysis. 2002. A Guide to the NIPAs. Washington: Bureau of Economic Analysis.

Burtraw, Dallas, Ranjit Bharvirkar, and Meghan McGuinness. 2003a. Uncertainty and the Net Benefits of NOx Emission Reductions from Electricity Generation. Land Economics 79 (3).

Burtraw, Dallas, Alan Krupnick, Karen Palmer, Anthony Paul, Mike Toman, and Cary Bloyd. 2003b. Ancillary Benefits of Reduced Air Pollution in the United States from Moderate Greenhouse Gas Mitigation Policies in the Electricity Sector. Journal of Environmental Economics and Management.

Dahl, Carol. 1993. A Survey of Energy Demand Elasticities in Support of the Development of the NEMS. Washington: Energy Information Administration.

Dubin, Jeffrey, and Daniel McFadden. 1984. An Econometric Analysis of Residential Electric Appliance Holdings and Consumption. Econometrica 52 (2):53-76.

EIA. 1993. Assessment of Energy Use in Multi-building Facilities. Washington, DC: EIA. . 1998. Impacts of the Kyoto Protocol on U.S. Energy Markets and Economic Activity. 1999. Model Documentation Report: Industrial Sector Demand Module of the National Energy Modeling System. Washington, DC: EIA.

—. 2000. Annual Energy Outlook 2001. Washington, DC: U.S. Energy Information Administration.

— 2001. Annual Energy Outlook 2002. Washington, DC: U.S. Energy Information Administration.

- 2002. Emissions of Greenhouse Gases in the United States 2001. Washington, DC.: EIA. 
Energy Modeling Forum. 1998. A Competitive Electricity Industry. Stanford: Energy Modeling Forum.

—. 2001. Prices and Emissions in a Competitive Electricity Sector. Stanford: Energy Modeling Forum.

Goldberg, Pinelopi. 1998. The Effects of Corporate Average Fuel Efficiency Standards in the US. Journal of Industrial Economics 46 (1):1-33.

Goldberger, A.S. 1968. The Interpretation and Estimation of Cobb-Douglas Functions. Econometrica 35 (3-4):464-472.

Greening, L.A., D.L. Greene, and C. Difiglio. 2000. Energy Efficiency and Consumption - the Rebound Effect - A Survey. Energy Policy 28 (6-7):389-401.

Harrington, Winston, James N. Sanchirico, and Margaret Walls. 2003. Effects of Climate Change Policies on the US Household Transportation Sector. Washington, DC: Resources for the Future.

Heckman, J. 1979. Sample Selection Bias as a Specification Error. Econometrica 47:153-161.

Herman, Shelby W. 2000. Fixed Assets and Consumer Durable Goods. Survey of Current Business 80 (4):17-30.

Kleit, Andrew N. 1990. The Effect of Annual Changes in Auto Fuel Economy Standards. Journal of Regulatory Economics 2:151-172.

Kwoka, John E. 1983. The Limits of Market-Oriented Regulatory Techniques: The Case of Automotive Fuel Economy. Quarterly Journal of Economics 98:695-704.

Lawson, Ann M. 1997. Benchmark Input-Output Accounts for the United States. Survey of Current Business 77 (11):36-82.

Maddala, G.S. 1983. Limited Dependent and Qualitative Variables in Econometrics. Edited by J.-M. Grandmont and C. F. Manski, Econometric Society Monographs. Cambridge, UK: Cambridge University Press.

Mannering, Fred, and Clifford Winston. 1985. A Dynamic Empirical Analysis of Household Vehicle Ownership and Utilization. The Rand Journal of Economics 16 (2):215-226.

Manski, Charles F, and E Goldin. 1983. An Econometric Analysis of Automobile Scrappage. Transportation Science 17 (4):365-375. 
McKibbin, Warwick, Martin Ross, Robert Shackleton, and Peter Wilcoxen. 1999. Emissions Trading, Capital Flows and the Kyoto Protocol. Washington, DC: Brookings Institution.

National Research Council. 2002. Effectiveness and Impact of Corporate Fuel Economy (CAFE) Standards. Washington, DC: National Academy Press.

Paul, Anthony, and Dallas Burtraw. 2002. The RFF Haiku Electricity Market Model. Washington: Resources for the Future.

Thorpe, Steven. 1997. Fuel Economy Standards, New Vehicle Sales, and Average Fuel Efficiency. Journal of Regulatory Economics 11:311-26.

Train, Kenneth. 1986. Qualitative Choice Analysis: Theory, Econometrics, and an Application to Automobile Demand. Cambridge, MA: MIT Press.

Wales, T.J., and A.D. Woodland. 1976. Estimation of Household Utility Functions and Labor Supply Response. International Economic Review 17 (2):397-410.

White, H. 1980. A Heteroskedasticity-Consistent Covariance Matrix Estimator and a Direct Test for Heteroskedasticity. Econometrica 48:817-38. 